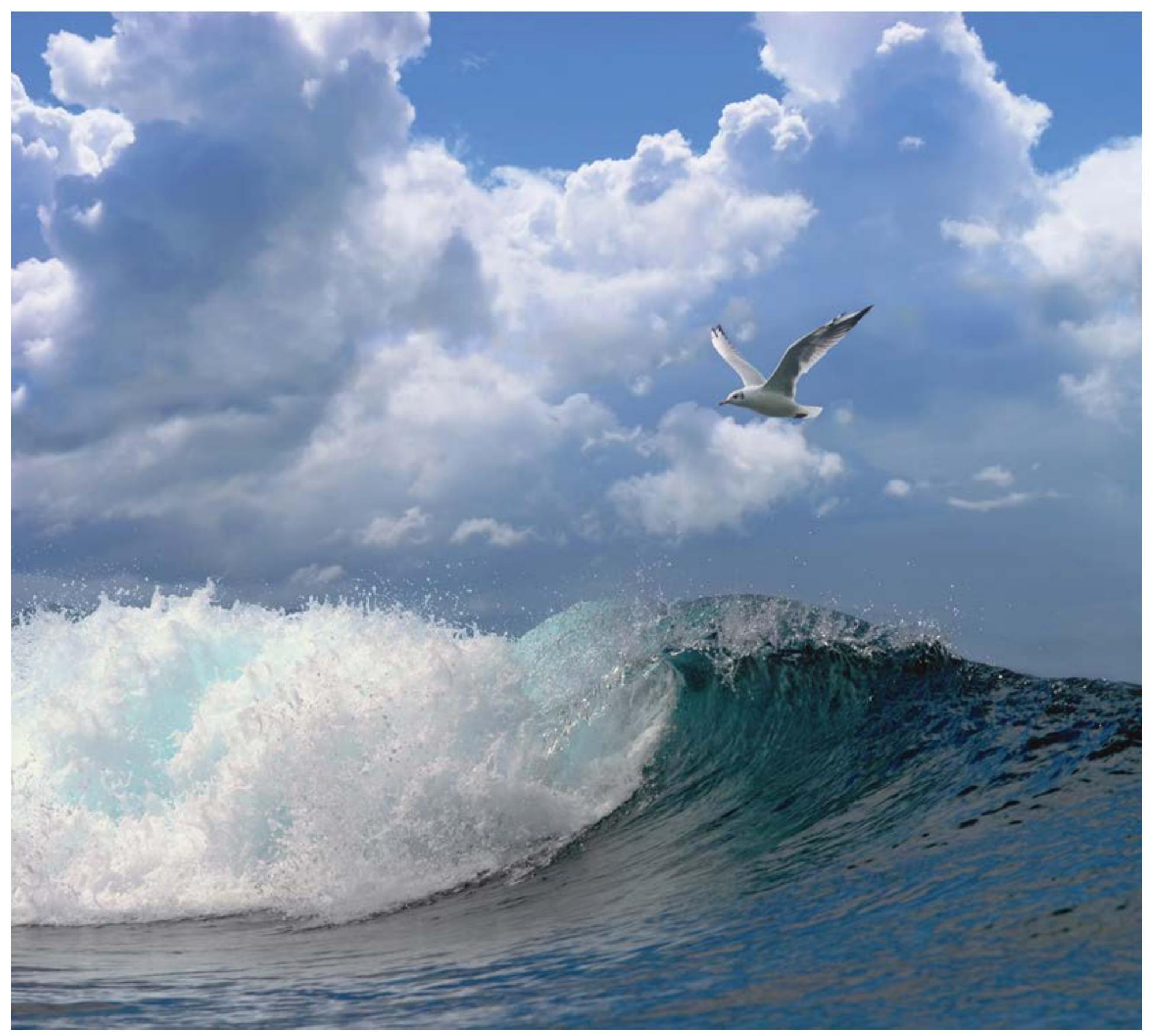

TBT-gehalten en effecten bij de Gewone Alikruik, de Gevlochten Fuikhoorn en de Purperslak langs de Nederlandse kust in 2016 


\section{TBT-gehalten en effecten bij de Gewone Alikruik, de Gevlochten Fuikhoorn en de Purperslak langs de Nederlandse kust in 2016}

M. Kotterman, J. J ol en E van Barneveld

rapport C110/16 [Vertrouwelijk, gedurende 6 maanden]

\section{Wageningen Marine Research}

Opdrachtgever:

RWS nummer

Publicatiedatum:
Rijkswaterstaat CIV Mervyn Roos

Postbus 17, 8200 AA Lelystad

RWS Centrale Informatievoorziening BM 16.13

15 november 2016 
Dit rapport is gratis te downloaden van https://doi.org/10.18174/406875

Wageningen Marine Research verstrekt geen gedrukte exemplaren van rapporten

\section{(c) 2016 Wageningen Marine Research}

Wageningen Marine Research, onderdeel van De Directie van Wageningen Marine Research is niet aansprakelijk voor Stichting Wageningen Research. gevolgschade, noch voor schade welke voortvloeit uit toepassingen van de resultaten KvK nr. 09098104,

IMARES BTW nr. NL 8113.83.696.B16. Code BIC/SWIFT address: RABONL2U van werkzaamheden of andere gegevens verkregen van Wageningen Marine Research; opdrachtgever vrijwaart Wageningen Marine Research van aanspraken van derden in verband met deze toepassing.

IBAN code: NL 73 RABO 0373599285

Dit rapport is vervaardigd op verzoek van de opdrachtgever hierboven aangegeven en is zijn eigendom. Niets uit dit rapport mag weergegeven en/of gepubliceerd worden, gefotokopieerd of op enige andere manier gebruikt worden zonder schriftelijke toestemming van de opdrachtgever. 


\section{I nhoudsopgave}

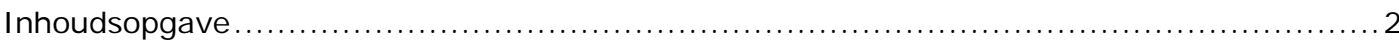

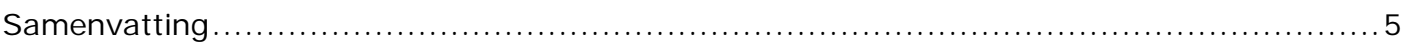

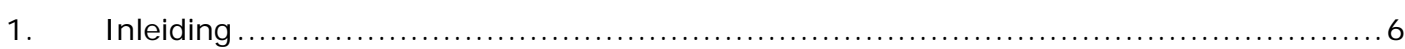

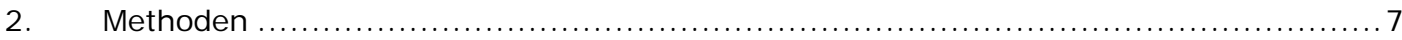

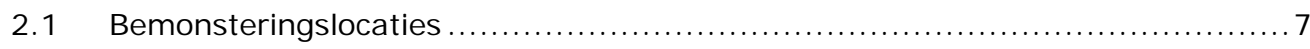

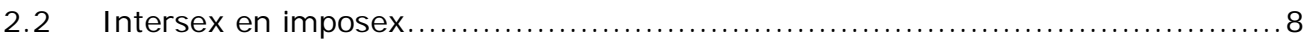

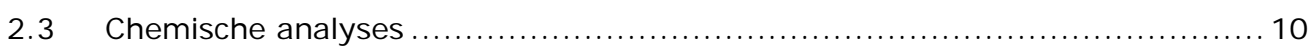

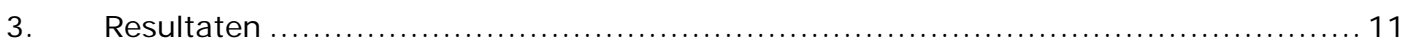

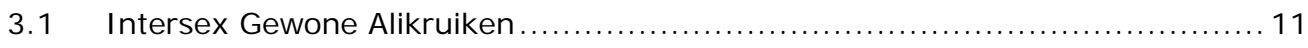

3.2 Imposex Gevlochten Fuikhoorns en Purperslakken ............................ 12

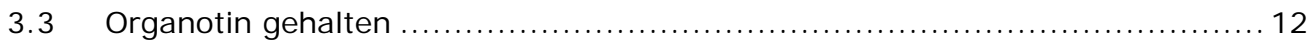

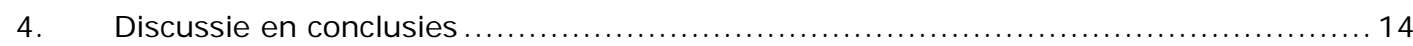

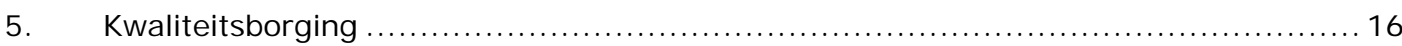

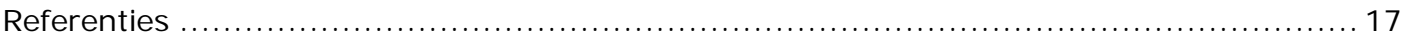

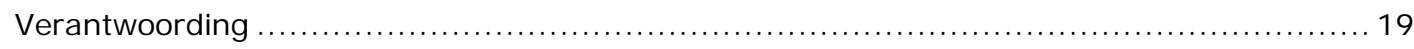

Bijlage 1. Resultaten intersex analyse Gewone Alikruiken................................ 20

Bijlage 1a. Resultaten individuele Alikruiken Waddenzee kustzone oost.................. 21

Bijlage 1b. Resultaten individuele Alikruiken Waddenzee kustzone west ...................22

Bijlage 2. Resultaten imposex analyse Gevlochten Fuikhoorns en Purperslakken ............... 23

Bijlage 2a. Resultaten individuele Fuikhoorns Hollandse kustzone noord .................. 24

Bijlage 2b. Resultaten individuele Fuikhoorns Hollandse kustzone midden ................. 25

Bijlage 2c. Resultaten individuele Fuikhoorns Hollandse kustzone zuid ..................... 26

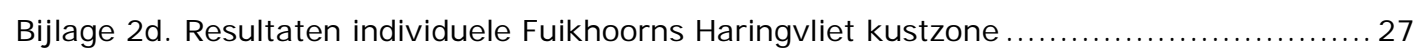

Bijlage 2e. Resultaten individuele Purperslakken Grevelingen kustzone .................... 28 
Bijlage 2f. Resultaten individuele Purperslakken Oosterschelde kustzone....

Bijlage 2g. Resultaten individuele Purperslakken Westerschelde kustzone. 30

Bijlage 3. Gehalten aan organotinverbindingen in 2016. 31

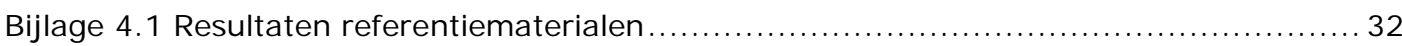

Bijlage 4.2 Resultaten ringonderzoek Quasimeme in biota (labcode: Q127 IMARES) 33

Bijlage 4.3 Rapportagegrenzen en meetonzekerheid. 34 


\section{Samenvatting}

Sinds 2005 analyseert IMARES in opdracht van Rijkswaterstaat (RI KZ, later de Waterdienst, heden CIV) het voorkomen van intersex bij de Gewone Alikruiken (Littorina littorea) die op vaste locaties langs de Nederlandse kust verzameld worden. Het doel van dit onderzoek is effecten van verontreiniging met organotinverbindingen vast te stellen.

Gewone Alikruiken zijn in vergelijking met andere gastropoden echter vrij ongevoelig voor TBT. Net als in 2012 t/m 2015 zijn in 2016 daarom naast de Gewone Alikruiken ook Gevlochten Fuikhoorns (Nassarius reticulatus) en Purperslakken (Nucella lapillus) verzameld. De Gevlochten Fuikhoorns zijn verzameld tijdens de schelpdierbemonsteringen die IMARES in opdracht van het Ministerie van EZ uitvoert. Voor de Purperslakken is een aparte bemonstering, speciaal voor dit onderzoek, uitgevoerd. Bij de Gevlochten Fuikhoorn en de Purperslak resulteert TBT in imposex verschijnselen, een gevoeligere parameter dan intersex.

Bij de Gewone Alikruik werden op geen van beide onderzochte locaties (Waddenzee kustzone Oost en West) intersex verschijnselen aangetroffen.

De vrouwelijke Gevlochten Fuikhoorns, bemonsterd op de locaties Hollandse kustzone Midden, Noord en Zuid, vertoonden op geen van de vier bemonsterde locaties verschijnselen van imposex.

Purperslakken werden bemonsterd op de locaties Grevelingen kustzone en op Oosterschelde en Westerschelde kustzone. Dit jaar werd alleen op de locatie Westerschelde kustzone imposex geconstateerdbBij 3 van de 21 onderzochte vrouwtjes (twee in stadium 1a en één in stadium 1c). Dit resulteerde in een VDSI waarde van 0,14. Dit is een afname in vergelijk met de voorgaande jaren (In 2015 0,50, 2014 1,12 en in 2013 0,89).

Op basis van de imposex-resultaten bij de Gevlochten Fuikhoorn en de Purperslak, vallen dit jaar alle onderzochte monsters in OSPAR Assessment Class A (VDSI Purperslak <0,3) of Class A/B (VDSI Gevlochten Fuikhoorn <0.3), ook de locatie Westerschelde kustzone. Dit is een verbetering ten opzichte van de voorgaande jaren. Het hoogste gemeten TBT-gehalte in de onderzochte monsters was, overeenkomstig met de geobserveerde imposex, in de locatie Westerschelde kustzone. 


\section{Inleiding}

Sinds 2005 analyseert IMARES het voorkomen van intersex bij Gewone Alikruiken (Littorina littorea) die op vaste locaties langs de Nederlandse kust verzameld worden. Het doel van dit onderzoek is effecten van verontreiniging met organotinverbindingen, specifiek tributyltinverbindingen (TBT), vast te stellen. De uitvoering geschiedt volgens het Projectplan chemisch meetnet MWTL 2015; “Monitoren van organotinverbindingen en biologische effecten in mariene slak 2015", auteur M.H. van der Weijden, van 27 oktober 2014 (dit projectplan is op 15 juli 2015 verstrekt).

Gewone Alikruiken zijn algengrazers en in vergelijking met andere gastropoden vrij ongevoelig voor TBT. Blootstelling aan TBT kan leiden tot intersex, een afwijking waarbij de vrouwelijke genitaliën vergroeien tot mannelijke genitaliën. Deze vrouwtjes zijn al volledig steriel vanaf stadium 2 (Oehlmann et al., 1996). Bij roofslakken resulteert blootstelling aan TBT in imposex. Hierbij ontwikkelen de vrouwtjes naast normale vrouwelijke genitaliën, ook mannelijke genitaliën, die uiteindelijk de oviduct (eileider) blokkeren, wat leidt tot steriliteit (en sterfte) in stadium 5 en 6 (Bauer et al., 1995). I mposex treedt al bij veel lagere TBT-gehalten op dan intersex.

De Purperslak (Nucella lapillus) is een van de gevoeligste soorten met betrekking tot TBT. Deze soort komt voor in de Zeeuwse wateren en vertoont voldoende variatie in imposex om een realistisch onderscheid te kunnen maken tussen locaties met betrekking tot de TBT belasting (Kaag \& Jol, 2007). Door de beperkte verspreiding is deze soort echter niet geschikt om als indicatorsoort voor de gehele Nederlandse kustzone te dienen.

Een alternatief is de Gevlochten Fuikhoorn (Nassarius reticulatus). Deze soort wordt sinds enkele jaren regelmatig aangetroffen tijdens de jaarlijkse schelpdiersurveys die IMARES in opdracht van het Ministerie van EZ uitvoert in de Nederlandse wateren. Ook de Gevlochten Fuikhoorn vertoont imposex en is gevoeliger dan de Gewone Alikruik, maar niet zo extreem gevoelig als de Purperslak (Stroben et al., 1992a; Bryan et al., 1993; Oehlmann et al., 1996). Vanaf 2009 zijn daarom niet alleen Gewone Alikruiken verzameld op de standaardlocaties, maar zijn ook op vijf locaties Gevlochten Fuikhoorns verzameld (Kaag et al., 2009). De keuze van de locaties was van te voren alleen globaal bepaald (monding Westerschelde, monding Europoort en voor de kust van Noord-Holland), aangezien niet bekend was waar de aantallen hoog genoeg zouden zijn voor het verzamelen van een voldoende groot monster. Tijdens de bemonsteringen in 2011 t/m 2016 is naast de Gewone Alikruik en de Gevlochten Fuikhoorn, tevens de Purperslak als indicatorsoort bemonsterd (Tabellen 2, 3 en 4) en is de Nederlandse kustzone ingedeeld in bemonsteringsgebieden. Hierdoor kunnen binnen een gebied kleine monsters van een soort samengevoegd worden. 


\section{Methoden}

\subsection{Bemonsteringslocaties}

Voor de bemonstering van slakken heeft RWS 9 aandachtsgebieden gedefinieerd (Tabel 1). In elk aandachtsgebied wordt 1 monster geanalyseerd.

In de Zeeuwse Delta zijn Purperslakken gezocht langs dijken, omdat de aantallen Gevlochten Fuikhoorns te laag zijn.

Tabel 1 Voorgestelde onderzoeklocaties waar de verschillende geplande indicatorsoorten volgens het projectplan uit 2015 bemonsterd dienen te worden (zie figuur 1 voor de ligging van de betreffende locaties)

\begin{tabular}{|llll|}
\hline Gebied & DONAR-code & Locatie & Geplande soort \\
\hline Waddenzee kustzone Oost & WADDZKZNOT & Eems-Dollard/Eemshaven & Gewone Alikruik \\
Waddenzee kustzone West & WADDZKZNWT & Waddenzee-West/Roptazijl & Gewone Alikruik \\
Hollandse kustzone Noord & HOLLSKZNND & Petten/Den Helder & Gevlochten fuikhoorn \\
Hollandse kustzone Midden & HOLLSKZNMDN & Monding Noordzeekanaal & Gevlochten Fuikhoorn \\
Hollandse kustzone Zuid & HOLLSKZNZD & Scheveningen & Gevlochten Fuikhoorn \\
Haringvliet kustzone & HARVKZNE & Monding Haringvliet & Purperslak \\
Grevelingen kustzone & GREVLGKZNE & Monding Grevelingen & Purperslak \\
Oosterschelde kustzone & OOSTSDKZNE & Monding Oosterschelde & Purperslak \\
Westerschelde kustzone & WESTSDKZNE & Monding Westerschelde & Purperslak \\
\hline
\end{tabular}

In figuur 1 zijn de onderzoeklocaties met hun bijbehorende DONAR-codes voor 2016 weergegeven die door de opdrachtgever in het projectplan zijn voorgesteld.

Bij de Gewone Alikruiken wordt de mate van intersex vastgesteld en wordt het organotin-gehalte in het weefsel van de dieren bepaald. Bij de Gevlochten Fuikhoorns en de Purperslakken wordt de mate van imposex vastgesteld en wordt eveneens het organotin-gehalte in het weefsel van de dieren bepaald. 


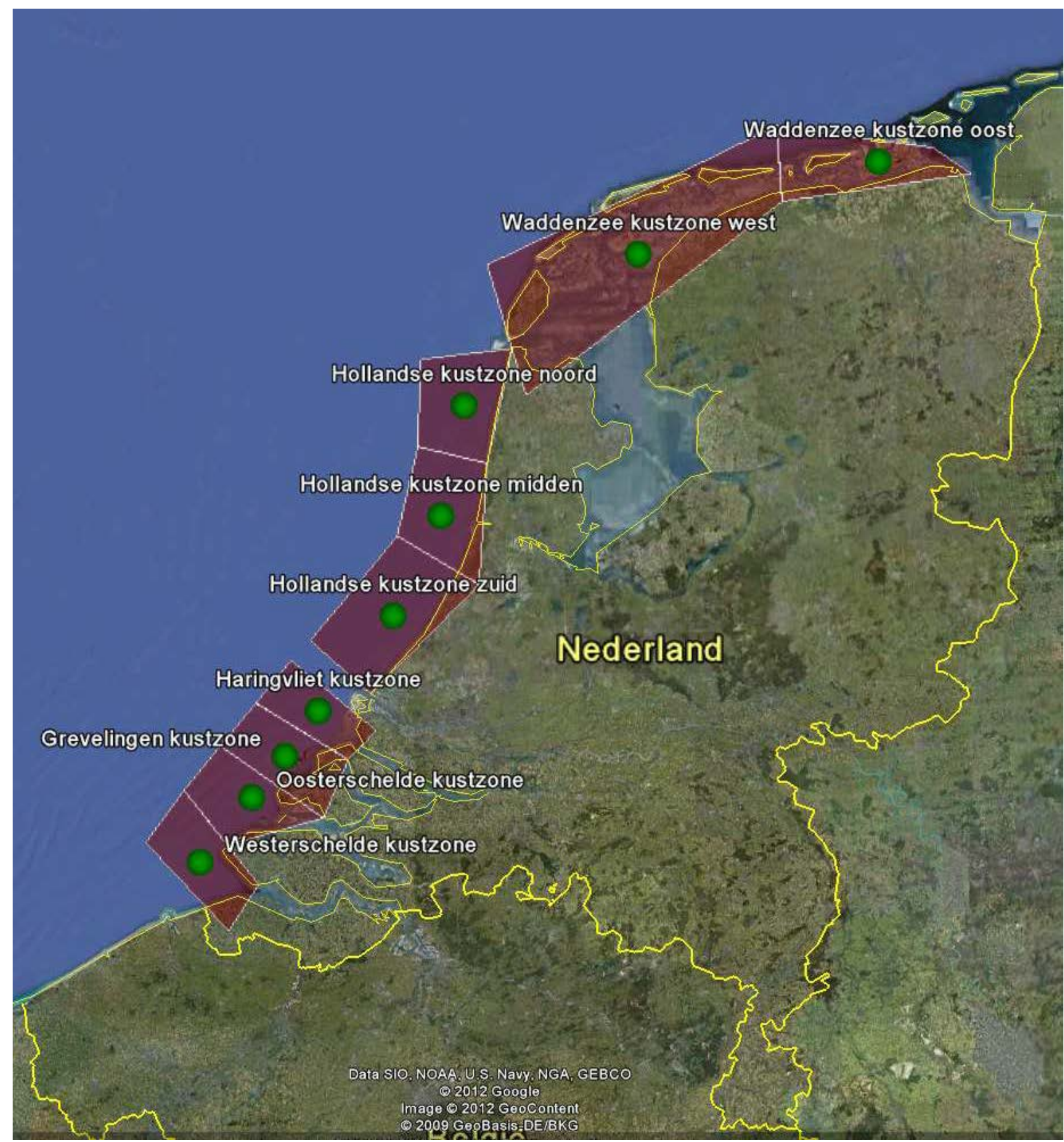

Figuur 1 Voorgestelde onderzoeklocaties in 2016 (uit Projectplan RWS 2015). De paarse vlakken geven de grenzen van de gebieden aan waarbinnen de slakken worden gezocht, de groene stippen het zwaartepunt van de locaties.

\section{$2.2 \quad$ Intersex en imposex}

Gewone Alikruiken werden op 22 juni 2016 verzameld, door handmatig op de dijk te rapen bij laag water, op twee Waddenzee locaties (Tabel 2). Op beide locaties zijn voldoende Gewone Alikruiken geraapt voor de analyse van exact 40 individuen (exact 40 exemplaren volgens richtlijn OSPAR en Projectplan 2015) op het voorkomen van intersex en chemische analyse van de weefsels op organotinverbindingen. De verzamelde Gewone Alikruiken zijn dezelfde dag gekoeld (koelbox met voldoende koelelementen) naar het laboratorium in Yerseke vervoerd. 
De intersex analyse is uitgevoerd conform J ol (2004). Intersex bij Gewone Alikruiken kan in een gradueel systeem geclassificeerd worden, waarbij 4 stadia worden onderscheiden, lopend van 0 (geen effect) tot 3 (volledig steriliteit).

De ISI (intersex index) is het gemiddelde intersex stadium van de populatie. De ISI wordt als volgt bepaald:

$I S I=$ som intersex stadia alle vrouwtjes/aantal vrouwtjes

Gevlochten Fuikhoorns zijn tussen 4 april en 9 mei 2016 verzameld tijdens de WOT schelpdierbemonstering (Tabel 3). Tijdens deze bemonstering worden de schelpdieren bemonsterd met de IMARES-bodemschaaf in raaien van 150 meter lang. De schaaf is $15 \mathrm{~cm}$ breed, zodat een totale oppervlak van 22,5 $\mathrm{m}^{2}$ wordt bemonsterd. Exact 40 exemplaren Gevlochten Fuikhoorns werden zo mogelijk nog dezelfde dag aan boord van het schip geanalyseerd.

Omdat in de Zeeuwse Delta niet voldoende Gevlochten Fuikhoorns aanwezig waren, hetgeen al een aantal jaren het geval is, werden hier op 24 mei 2016 Purperslakken tijdens een aparte bemonstering speciaal voor dit project (Tabel 4). Purperslakken bevinden zich in het intertijdegebied en worden bij laag water handmatig van de stenen geraapt. Exact 40 exemplaren zijn onderzocht.

De imposex-analyse in beide organismen is uitgevoerd conform Jol (2007). Imposex bij Gevlochten Fuikhoorns en Purperslakken kan in een gradueel systeem geclassificeerd worden, lopend van 0 (geen effect) tot 4 (Gevlochten Fuikhoorn) of 6 (Purperslak). Er zijn geen aanwijzingen dat bij de Gevlochten Fuikhoorn steriliteit optreedt (stadia 5 en 6 ).

De belangrijkste karakteristiek voor de populatie is de VDSI (Vas Deferens Sequence Index). Dit is het gemiddelde imposex stadium in de populatie. De VDSI wordt als volgt bepaald:

VDSI $=\frac{\sum(\text { intersex stadia van alle vrouwtjes })}{\text { totale aantal vrouwtjes }}$

Daarnaast kan ook de Relative Penis Size worden uitgedrukt in een index (RPSI). De RPSI wordt als volgt bepaald:

$\mathrm{RPSI}=\begin{gathered}\text { (gemiddelde lengte van de penis van alle onderzochte vrouwtjes) } \\ \text { (gemiddelde penislengte van alle mannetjes) }\end{gathered}$

Alle onderzochte dieren zijn voorbehandeld voor de analyse op organotinverbindingen. Deze voorbehandeling bestaat uit het zoveel mogelijk verwijderen van de schaal en operculum (afsluiting mondopening), schoonspoelen en invriezen. De ingevroren monsters zijn naar het laboratorium van I MARES in IJ muiden gebracht voor analyse op organotingehalten. 


\subsection{Chemische analyses}

Voor elk monster is van de weefsels van alle op intersex en imposex onderzochte slakken een mengmonster gemaakt t.b.v. organotinanalyses.

Onderstaande stoffen zijn geanalyseerd en gerapporteerd als gehalte $\mathrm{Sn}$ en kation. In het rapport zullen verder de volgende afkortingen gebruikt worden om de stof aan te duiden.

\begin{tabular}{|lll|}
\hline Stofnaam & Afkorting & CAS nummer \\
\hline Tributyltin & TBT & $688-73-3$ \\
Dibutyltin & DBT & $1002-53-5$ \\
Monobutyltin & MBT & $78763-54-9$ \\
Trifenyltin & TPhT & $668-34-8$ \\
Difenyltin & DPhT & $1011-95-6$ \\
Monofenyltin & MPhT & $2406-68-0$ \\
\hline
\end{tabular}

De volgende analysemethoden zijn toegepast:

Organotin:

Zes organotinverbindingen worden gerapporteerd (MBT, DBT, TBT, MPhT, DPhT en TPhT) als Sn en als kation. I onogene organotinverbindingen komen via een schudextractie met methanol, azijnzuur en hexaan beschikbaar voor alkylering. Vervolgens worden de alkyltinverbindingen geëthyleerd met natriumtetraethylboraat. Na een clean-up met aluminiumoxide worden de extracten geanalyseerd met behulp van GC-MS (SIM mode).

De methode is vastgelegd in IMARES ISW 2.10.3.024 Dierlijk weefsel. "Bepalen van het gehalte aan organotinverbindingen na extractie en derivatisatie; GC-EI-MS" en is geaccrediteerd door de Raad van Accreditatie (testlaboratoriumnummer L097, verrichting nummer 18).

\section{Droge stof:}

Voor de bepaling van het droge stofgehalte wordt het gewogen monster gemengd met een oppervlakte vergrotende stof, vervolgens gedroogd in een stoof ( $105^{\circ} \mathrm{C}, 3$ uur) en na afkoelen in een exsiccator teruggewogen.

De methode is vastgelegd in IMARES ISW 2.10.3.011 Dierlijk weefsel. "Bepalen van het gehalte aan vocht; gravimetrie" en is geaccrediteerd door de Raad voor Accreditatie (testlaboratoriumnummer L097, verrichting nummer 2 ). 


\section{Resultaten}

De resultaten vermeld in dit rapport zijn alleen van toepassing op de geanalyseerde monsters.

In de tabellen 2, 3 en 4 zijn de posities aangegeven waar in 2016 Gewone Alikruiken, Gevlochten Fuikhoorns en Purperslakken bemonsterd zijn. Deze posities betreffen het zwaartepunt van de door RWS in het Projectplan opgegeven hoekpunten voor één locatie. Binnen één locatie kunnen op meerdere plekken slakken bemonsterd zijn en samengevoegd tot één mengmonster. Tevens zijn de bemonsterdata, locatienamen en de bijbehorende DONAR locatiecodes weergegeven.

Tabel 2 Datum van bemonstering Gewone Alikruiken en posities in de monstergebieden

\begin{tabular}{|lllllll|}
\hline Datum & \multirow{2}{*}{ Locatienaam } & \multirow{2}{*}{ DONAR-code } & \multicolumn{2}{c|}{ Coördinaten (WGS84) } & \multicolumn{2}{c|}{ Coördinaten (format DI A) } \\
& & & E & N & X & Y \\
\hline $22 / 06 / 2016$ & \multirow{2}{*}{ Waddenzee kustzone Oost } & WADDZKZNOT & $6^{\circ} 28.54^{\prime}$ & $53^{\circ} 29.13^{\prime}$ & 006283283 & 053290758 \\
$22 / 06 / 2016$ & \multirow{2}{*}{ Waddenzee kustzone West } & WADDZKZNWT & $5^{\circ} 19.96^{\prime}$ & $53^{\circ} 13.76^{\prime}$ & 005195792 & 053134560 \\
\hline
\end{tabular}

Tabel 3 Datum van bemonstering Gevlochten Fuikhoorns en posities in de monstergebieden

\begin{tabular}{|lllllll|}
\hline Datum & \multirow{2}{*}{ Locatienaam } & DONAR-code & \multicolumn{2}{c|}{ Coördinaten (WGS84) } & \multicolumn{2}{c|}{ Coördinaten (format DI A) } \\
& & & E & N & X & Y \\
\hline 05/04/2016 & Hollandse kustzone Noord & HOLLSKZNND & $4^{\circ} 31.24^{\prime}$ & $52^{\circ} 48.09^{\prime}$ & 004311444 & 052480536 \\
05/04/2016 & Hollandse kustzone Midden & HOLLSKZNMDN & $4^{\circ} 25.02^{\prime}$ & $52^{\circ} 29.45^{\prime}$ & 004250100 & 052292709 \\
04/04/2016 & Hollandse kustzone Zuid & HOLLSKZNZD & $4^{\circ} 12.15^{\prime}$ & $52^{\circ} 12.50^{\prime}$ & 004120880 & 052122995 \\
$09 / 05 / 2016$ & Haringvliet kustzone & HARVKZNE & $3^{\circ} 51.93^{\prime}$ & $51^{\circ} 56.25^{\prime}$ & 003515590 & 051561495 \\
\hline
\end{tabular}

Tabel 4 Datum van bemonstering Purperslakken en posities in de monstergebieden

\begin{tabular}{|lllllll|}
\hline Datum & \multirow{2}{*}{ Locatienaam } & DONAR-code & \multicolumn{2}{c|}{ Coördinaten (WGS84) } & \multicolumn{2}{c|}{ Coördinaten (format DI A) } \\
& & & E & N & X & Y \\
\hline $24 / 05 / 2016$ & Grevelingen kustzone & GREVLGKZNE & $3^{\circ} 43.05^{\prime}$ & $51^{\circ} 48.48^{\prime}$ & 003430300 & 051482900 \\
$24 / 05 / 2016$ & Monding Oosterschelde & OOSTSDKZNE & $3^{\circ} 34.17^{\prime}$ & $51^{\circ} 41.39^{\prime}$ & 003341009 & 051412330 \\
$24 / 05 / 2016$ & Monding Westerschelde & WESTSDKZNE & $3^{\circ} 20.45^{\prime}$ & $51^{\circ} 30.21^{\prime}$ & 003202679 & 051301316 \\
\hline
\end{tabular}

Bij de bemonstering kon aan het schema van het projectplan worden voldaan. Voor de laatste 3 genoemde locaties is wel van de in het projectplan voorgestelde soort afgeweken (Purperslak i.p.v. Gevlochten Fuikhoorn). Gevlochten Fuikhoorns zijn nl. onvoldoende aangetroffen in de Zeeuwse Delta in de voorgaande jaren. Purperslak is weliswaar een gevoeliger soort, maar wordt onvoldoende aangetroffen in de rest van de Nederlandse kustzone om ook daar als indicatorsoort te dienen. De resultaten van alle afzonderlijke monsters worden zowel in dit rapport als in de DIF t.b.v. ICES gerapporteerd.

\subsection{Intersex Gewone Alikruiken}

In bijlage 1 zijn de resultaten weergegeven van de intersex analyse in de Gewone Alikruiken, in tabel 5 zijn de resultaten voor intersex samengevat. 
Tabel 5. Resultaten intersex analyse Alikruiken 2016

\begin{tabular}{|c|c|c|c|}
\hline Locatie & Soort & $\begin{array}{c}\text { Aantal vrouwtjes } \\
\text { (met intersex) }\end{array}$ & ISI \\
\hline Waddenzee kustzone Oost & Gewone Alikruik & $14(0)$ & 0.00 \\
\hline Waddenzee kustzone West & Gewone Alikruik & $25(0)$ & 0.00 \\
\hline
\end{tabular}

In 2016 werd geen intersex waargenomen in de geanalyseerde Gewone Alikruiken. Ongeveer de helft van de onderzochte exemplaren bestond uit vrouwtjes (Tabel 5).

\subsection{I mposex Gevlochten Fuikhoorns en Purperslakken}

In bijlage 2 zijn de volledige resultaten weergegeven van de imposex analyse van Gevlochten Fuikhoorns en Purperslakken, in tabel 6 zijn de resultaten voor imposex samengevat.

Tabel 6 Resultaten imposex analyse 2016

\begin{tabular}{|c|c|c|c|c|c|}
\hline Locatie & Soort & $\begin{array}{c}\text { Aantal vrouwtjes } \\
\text { (met imposex) }\end{array}$ & $\begin{array}{c}\text { Aantal } \\
\text { (Stadium) }\end{array}$ & VDSI & RPSI \\
\hline Hollandse kustzone Noord & Gevlochten Fuikhoorn & $30(0)$ & $30(0)$ & 0.00 & 0.000000 \\
\hline Hollandse kustzone midden & Gevlochten fuikhoorn & $27(0)$ & $27(0)$ & 0.00 & 0.000000 \\
\hline Haringvliet kustzone & Gevlochten Fuikhoorn & $18(0)$ & $18(0)$ & 0.00 & 0.000000 \\
\hline Grevelingen kustzone & Purperslak & $24(0)$ & $24(0)$ & 0.00 & 0.000000 \\
\hline Oosterschelde kustzone & Purperslak & $24(0)$ & $24(0)$ & 0.00 & 0.000000 \\
\hline
\end{tabular}

Bij de Gevlochten Fuikhoorns werden op geen van de vier bemonsterde locaties vrouwtjes met verschijnselen van imposex aangetroffen (Tabel 6).

Bij de Purperslak werd op de locaties Grevelingen kustzone en Oosterschelde kustzone geen imposex geconstateerd. Op de locatie Westerschelde kustzone werd bij 3 van de 21 onderzochte vrouwtjes imposex geconstateerd ( 2 in stadium $1 a, 1$ in stadium 1c), resulterend in een VDSI van 0,14. Ongeveer de helft van de onderzochte exemplaren bestond uit vrouwtjes (Tabel 6). Zie ook figuur 2 in hoofdstuk 4.

\subsection{Organotin gehalten}

De analyses van de organotinverbindingen en van droge stof zijn in augustus 2016 uitgevoerd in het laboratorium van I MARES locatie IJ muiden.

Voor de bepaling van de organotinverbindingen voldoen de metingen aan de kwaliteitscriteria, zoals gesteld in het geaccrediteerde werkvoorschrift. Aangezien de metingen van de organotinverbindingen voldoen aan alle kwaliteitscriteria, zoals genoemd in betreffend ISW, zijn de gerapporteerde gehalten als normale waarden (met kwaliteitswaardecode 0) gerapporteerd. Aangezien alleen de metingen van TBT en DBT onder accreditatie vallen, worden alleen deze resultaten met het kwaliteitskenmerk Q gerapporteerd.

De concentratie TBT kation varieerde van $1.4 \mu \mathrm{g} / \mathrm{kg}$ (Gevlochten Fuikhoorn, Hollandse kustzone midden) tot $7.6 \mu \mathrm{g} / \mathrm{kg}$ (Purperslakken, Westerschelde kustzone). De volledige resultaten van de analyses aan organotinverbindingen in Gewone Alikruiken, Gevlochten Fuikhoorns en Purperslakken zijn weergegeven in bijlage 3.

Op 12 augustus 2013 is Richtlijn 2013/39/EU tot wijziging van Richtlijnen 2000/60/EG en 2008/105/EG betreffende prioritaire stoffen op het gebied van het waterbeleid gepubliceerd. In deze richtlijn is TBT 
weliswaar aangewezen als prioritair gevaarlijke stof, maar er is geen norm voor TBT in biota in deze richtlijn opgenomen.

In bijlage 4.1 zijn de gemeten gehalten in een mee-geanalyseerd referentiemateriaal weergegeven. Het betreft het gecertificeerde referentiemateriaal mossel (CRM CE-477).

De door IMARES gemeten gehalten in dit monster worden voor de componenten TBT, DBT en MBT

binnen de 2s-grenzen van de gecertificeerde waarden teruggevonden en kunnen dus als goed gekwalificeerd worden.

Voor de overige organotin componenten zijn geen gecertificeerde waarden vastgesteld voor dit CRM.

In bijlage 4.2 zijn de resultaten van deelname aan Quasimeme ringonderzoeken weergegeven.

De z-scores van ronde 2015,1 voldeden alle aan het door Quasimeme gestelde criterium. Bij ronde 2015, 2 en 2016, 1 werd in de ringonderzoekmonsters bij TBT een storende piek waargenomen welke normaal gesproken niet in monsters voorkomt. Deze piek is tot op heden alleen waargenomen in ringonderzoek materiaal en niet in regulier monstermateriaal.

Voor MBT werd een z-score behaald van -2.35 in ronde 2015,2 en -1.28 en -2.04 in ronde $2016,1$.

In bijlage 4.3 zijn de rapportagegrenzen van de monsters weergegeven.

De OSPAR richtlijn voor de rapportagegrens voor TBT is $1 \mu \mathrm{g} / \mathrm{kg}$ nat gewicht uitgedrukt als kation en 0.4 $\mu \mathrm{g} / \mathrm{kg}$ nat gewicht uitgedrukt als Sn (OSPAR Agreement, 2008-09).

De rapportagegrenzen bij de toegepaste methode worden afgeleid van de laagste gemeten standaard. Vanwege verschillen in ingewogen hoeveelheden zouden eigenlijk verschillende rapportagegrenzen per monster gerapporteerd moeten worden. Echter, een compromis voor de rapportagegrenzen, berekend aan de hand van de gemiddelde inweeg van de monsters, is weergegeven in bijlage 4.3 op verzoek van de opdrachtgever. De gerapporteerde rapportagegrenzen $(0.3 \mu \mathrm{g} / \mathrm{kg}$ nat gewicht uitgedrukt als kation en $0.1 \mu \mathrm{g} / \mathrm{kg}$ nat gewicht uitgedrukt als $\mathrm{Sn}$ ) voldoen ruimschoots aan boven gestelde richtlijn voor de rapportagegrenzen voor TBT.

Alle TBT-gehalten liggen ruim boven deze rapportagegrenzen. 


\section{Discussie en conclusies}

\section{Intersex:}

Op geen van beide bemonsterde locaties werden intersex-verschijnselen gevonden bij de Gewone Alikruiken. Door hun geringe gevoeligheid voor TBT vertonen de Gewone Alikruiken geen verschijnselen van intersex. De gehalten TBT in de Gewone Alikruiken op de bemonsterde locaties zijn ook laag.

\section{Imposex:}

In 2009 zijn voor het eerst Gevlochten Fuikhoorns verzameld langs de Nederlandse kust. Deze vertoonden in beperkte mate verschijnselen van imposex (Kaag et al., 2009). In 2010 t/m 2015 werden wederom Gevlochten Fuikhoorns verzameld. Ten Zuiden van de Nieuwe Waterweg werden echter te weinig Gevlochten Fuikhoorns gevonden. Er is daarom voor gekozen hier Purperslakken te bemonsteren. Om kleinere monsters samen te kunnen voegen tot een groot monster en om de analyse van Purperslakken aan te laten sluiten op die van de Gevlochten Fuikhoorns, zijn in 2011 wat grotere bemonsteringsgebieden vastgesteld. In 2013 zijn hiervan de definitieve begrenzingen met vaste coördinaten voor hoekpunten bekend geworden. Alle 9 te bemonsteren gebieden konden hierdoor in 2013 t/m 2016 binnen de aangegeven grenzen bemonsterd worden. In 2013 t/m 2016 konden ook Purperslakken bemonsterd worden in de Westerschelde kustzone.

De resultaten van de afgelopen 8 jaar zijn weergegeven in Figuur 2. Verschijnselen van imposex zijn dit jaar slechts op 1 van de 9 bemonsterde gebieden waargenomen. Hierbij moet rekening gehouden worden met het feit dat de mate van imposex die wordt geconstateerd mede afhankelijk is van de onderzochte indicatorsoort.

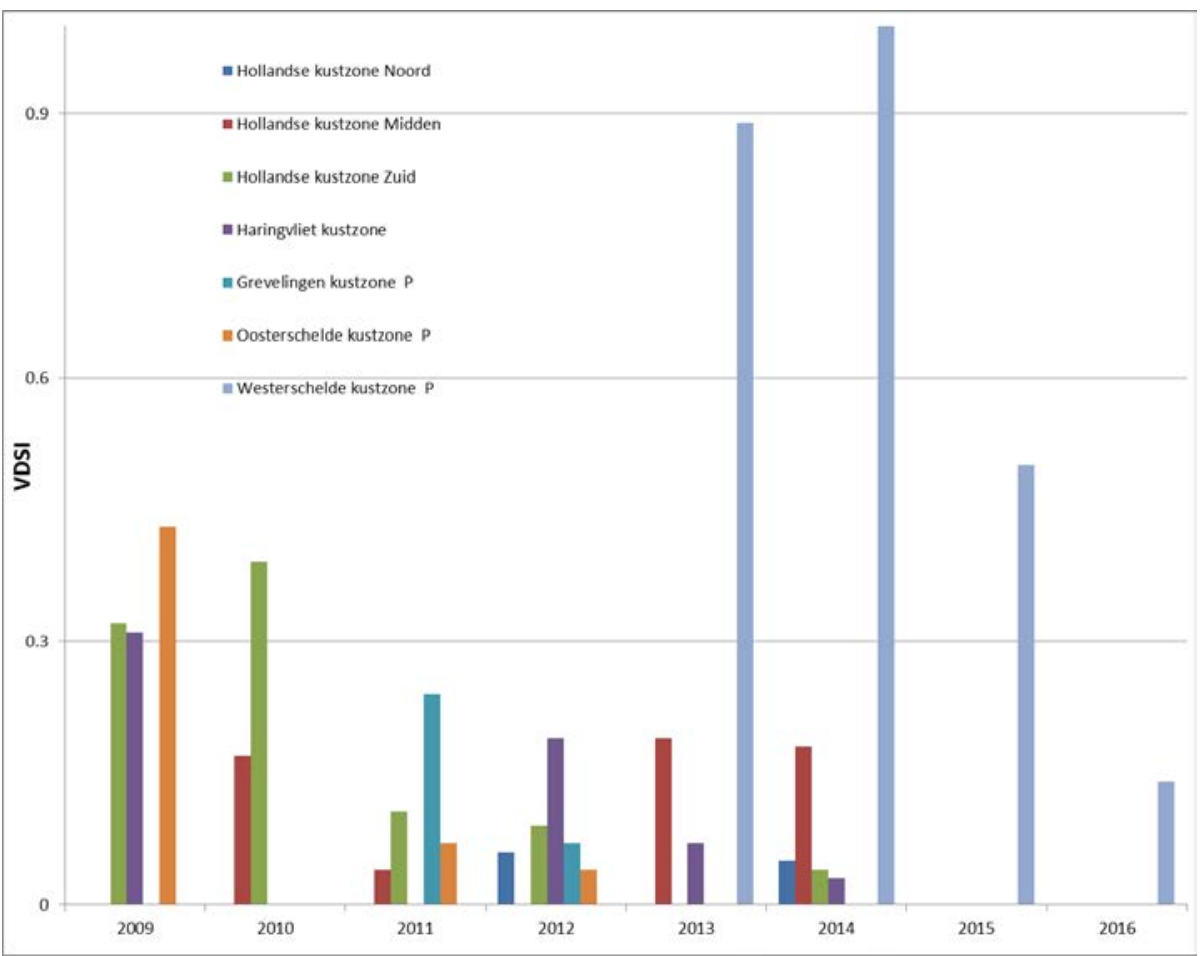

Figuur 2. Imposex index-VDSI in Gevlochten Fuikhoorns en Purperslak (P) langs de Nederlandse kust. De grenswaarde van de laagste EAC bedraagt VDSI 0,3 
De VDSI van de Gevlochten Fuikhoorns valt in de jaren 2011 t/m 2015 in OSPAR Assessment Class A/B (VDSI <0,3) (OSPAR, 2003; 2004). In 2015 en 2016 was de VDSI van de Gevlochten Fuikhoorns zelfs 0,00 . Ook de VDSI van de Purperslak (een nog gevoeliger soort) in Grevelingen kustzone en Oosterschelde kustzone vertoont dit beeld. Voor deze soort was de VDSI in de jaren 2011 t/m 2015 $<0$, 3, waarmee de desbetreffende locaties Assessment Class A scoren. Voor 2015 en ook in 2016 was de VDSI van de Purperslakken op beide locaties zelfs 0,00. Alleen de Westerschelde kustzone scoorde de afgelopen jaren Assessment Class B (VDSI purperslak 0,3 - <2,0), maar is nu ook verbeterd naar OSPAR Assessment Class A/B (VDSI <0,3).

Organotinverbindingen in relatie tot effecten bij slakken:

Geconcludeerd kan worden dat in de laatste jaren weinig effecten van TBT gevonden zijn bij slakken in de Nederlandse kustzone, dit komt overeen met de lage TBT-gehalten in het vlees van de dieren. Alleen de purperslakken uit Westerschelde kustzone vertoonden in 2016 imposex, de gehalten van DBT en vooral TBT waren hoger dan op de andere locaties. 


\section{Kwaliteitsborging}

I MARES beschikt over een ISO 9001:2008 gecertificeerd kwaliteitsmanagementsysteem (certificaatnummer: 187378-2015-AQ-NLD-RvA). Dit certificaat is geldig tot 15 september 2018. De organisatie is gecertificeerd sinds 27 februari 2001. De certificering is uitgevoerd door DNV Certification B.V.

Het chemisch laboratorium te IJ muiden beschikt over een NEN-EN-ISO/IEC 17025:2005 accreditatie voor testlaboratoria met nummer L097. Deze accreditatie is geldig tot 1 april 2017 en is voor het eerst verleend op 27 maart 1997; deze accreditatie is verleend door de Raad voor Accreditatie. Het chemisch laboratorium heeft hierdoor aangetoond in staat te zijn op technisch bekwame wijze valide resultaten te leveren en te werken volgens de ISO17025 norm. De scope (L097) met de geaccrediteerde analysemethoden is te vinden op de website van de Raad voor Accreditatie (www.rva.nl).

Op grond van deze accreditatie is het kwaliteitskenmerk $\mathrm{Q}$ toegekend aan de resultaten van die componenten die op de scope staan vermeld, mits aan alle kwaliteitseisen is voldaan.. Het kwaliteitskenmerk Q staat vermeld in de tabellen met de onderzoeksresultaten. Indien het kwaliteitskenmerk $\mathrm{Q}$ niet staat vermeld is de reden hiervan vermeld.

De kwaliteit van de analysemethoden wordt op verschillende manieren gewaarborgd. De juistheid van de analysemethoden wordt regelmatig getoetst door deelname aan ringonderzoeken waaronder die georganiseerd door QUASIMEME. Indien geen ringonderzoek voorhanden is, wordt een tweede lijnscontrole uitgevoerd. Tevens wordt bij iedere meetserie een eerstelijnscontrole uitgevoerd. Naast de lijnscontroles wordende volgende algemene kwaliteitscontroles uitgevoerd:

- Blanco onderzoek.

- Terugvinding (recovery).

- Interne standaard voor borging opwerkmethode.

- Injectie standard.

- Gevoeligheid.

Bovenstaande controles staan beschreven in IMARES werkvoorschrift ISW 2.10.2.105.

Indien gewenst kunnen gegevens met betrekking tot de prestatiekenmerken van de analysemethoden bij het chemisch laboratorium worden opgevraagd.

Indien sprake is van onbeheerste kwaliteit worden passende maatregelen genomen. 


\section{Referenties}

Bauer B., P. Fioroni, I. Ide, S. Liebe, J. Oehlmann, E. Stroben \& B. Watermann (1995) TBT effects on the female genital system of Littorina littorea: A possible indicator of tributyltin pollution. Hydrobiologia 309: 15-27.

Bryan G.W., G.R. Burt, P.E. Gibbs \& P.L. Pascoe (1993) Nassarius reticulatus (Nassariidae: Gastropoda) as an indicator of tributyltin pollution before and after TBT restrictions. J. Mar. Biol. Ass. U.K. 73(4): 913-929.

Gibbs P.E., G.W. Bryan, P.L. Pascoe \& G.R. Burt (1987) The use of the dog-whelk, Nucella lapillus, as an indicator of tributyltin (TBT) contamination. J. Mar. Biol. Ass. U.K. 67:507-523.

Gibbs P.E. (1999) Biological effects of contaminants: Use of imposex in the dogwhelk (Nucella lapillus) as a bioindicator of tributyltin pollution. ICES Techniques in Marine Environmental Sciences, No. 24.

EU-RL 2013/39/EU. Richtlijn 2013/39/EU tot wijziging van Richtlijnen 2000/60/EG en 2008/105/EG betreffende prioritaire stoffen op het gebied van het waterbeleid, op 12 augustus 2013 gepubliceerd in het EU-Publicatieblad.

Hoek-van Nieuwenhuizen M. \& J. Jol (2011) TBT-gehalten en effecten bij de Gewone Alikruik, de Gevlochten Fuikhoorn en de Purperslak langs de Nederlandse kust in 2011. I MARES rapport C120/11A.

Hoek-van Nieuwenhuizen, M. \& J. Jol en N.H.B.M. Kaag (2012) TBT-gehalten en effecten bij de Gewone Alikruik, de Gevlochten Fuikhoorn en de Purperslak langs de Nederlandse kust in 2012. IMARES rapport $\mathrm{C} 112 / 12$.

Hoek-van Nieuwenhuizen, M. \& J. Jol en N.H.B.M. Kaag (2013) TBT-gehalten en effecten bij de Gewone Alikruik, de Gevlochten Fuikhoorn en de Purperslak langs de Nederlandse kust in 2013. IMARES rapport $\mathrm{C} 176 / 13$.

Hoek-van Nieuwenhuizen, M. \& J. Jol en N.H.B.M. Kaag (2014) TBT-gehalten en effecten bij de Gewone Alikruik, de Gevlochten Fuikhoorn en de Purperslak langs de Nederlandse kust in 2014. IMARES rapport C148/14.

M. Hoek-van Nieuwenhuizen, J. Jol en N.H.B.M. Kaag (2015) TBT-gehalten en effecten bij de gewone Alikruik, de Gevlochten Fuikhoorn en de Purperslak langs de Nederlandse kust in 2015. IMARES rapport C147/15

Jol J . (2004) Vaststellen van intersex bij de Gewone Alikruik (Littorina littorea L.). RIKZ standaardvoorschrift SPECIE-11.

Jol J. (2007) Vaststellen van imposex bij de Purperslak (Nucella lapillus L.). RI KZ standaardvoorschrift SPECIE-12.

Kaag N.H.B.M. \& J. Jol (2007) Monitoring imposex bij de purperslak, Nucella lapillus, in de Zeeuwse wateren. IMARES rapport $\mathrm{C} 112 / 07$.

Kaag N.H.B.M., J. Jol \& M. Hoek-van Nieuwenhuizen (2009) TBT-gehalten en effecten bij de Gewone Alikruik (Littorina littorea) en de Gevlochten Fuikhoorn (Nassarius reticulatus) langs de Nederlandse kust in 2009. I MARES rapport C113/09.

Kaag N.H.B.M., J. Jol \& M. Hoek-van Nieuwenhuizen (2010) TBT-gehalten en effecten bij de Gewone Alikruik (Littorina littorea) en de Gevlochten Fuikhoorn (Nassarius reticulatus) langs de Nederlandse kust in 2010. IMARES rapport C130/10. 
Oehlmann J., E. Stroben, U. Schulte-Oehlmann, B. Bauer, P. Fioroni \& B. Markert (1996) Tributyltin biomonitoring using prosobranchs as sentinel organisms. Fresenius J. Anal. Chem. 354(5-6):540545.

OSPAR (2003) Harmonisation of criteria for the assessment of TBT-specific biological effects. OSPAR MON $03 / 3 / 1-E$.

OSPAR (2004) Provisional JAMP Assessment Criteria for TBT - Specific Biological Effects. OSPAR Agreement 2004-15.

OSPAR (2008) J AMP Guidelines for Contamination Specific Biological Effects. OSPAR Agreement 2008-09.

Standaard voorschrift A646. Analyse van butyltin en phenyltin verbindingen in mosselen, RIKZ, Haren, 1999.

Stroben E., J. Oehlmann \& P. Fioroni (1992a) Hinia reticulata and Nucella lapillus. Comparison of two gastropod tributyltin bioindicators. Mar. Biol. 114:289-296.

Stroben E., J. Oehlmann \& P. Fioroni (1992b) The morphological expression of imposex in Hinia reticulata (Gastropoda: Buccinidae): A potential indicator of tributyltin pollution. Mar. Biol. 113(4):625-636.

Weijden, M.H. van der (2015). Projectplan chemisch meetnet MWTL 2014. Monitoring van organotinverbindingen en biologische effecten in mariene slak, 27 oktober 2014 (concept). 


\section{Verantwoording}

\section{Rapport C110/16}

Projectnummer: 4316100017

Dit rapport is met grote zorgvuldigheid tot stand gekomen. De wetenschappelijke kwaliteit is intern getoetst door een collega-onderzoeker.

Akkoord:

Dr. T.P. Bult

Director

Handtekening:

Datum:

Handtekening:
15 november 2016

15 november 2016 


\section{Bijlage 1. Resultaten intersex analyse Gewone Alikruiken}

\begin{tabular}{|c|c|c|c|c|c|c|c|c|c|c|c|c|c|c|}
\hline \multirow[t]{2}{*}{ RQ-nummer } & \multirow{3}{*}{ |LIMS-nr. } & \multirow{3}{*}{$\begin{array}{l}\text { Monster } \\
\text { soort }\end{array}$} & \multirow[t]{3}{*}{ Locatie } & \multirow{2}{*}{ DONAR code } & \multirow{3}{*}{ Monsterdatum } & \multirow{2}{*}{$\begin{array}{c}\text { Aantal } \\
\text { onderzocht }\end{array}$} & \multirow{3}{*}{$\begin{array}{c}\text { Aantal } \\
\text { vrouwtjes }\end{array}$} & \multirow{3}{*}{$\begin{array}{c}\text { Gemiddelde } \\
\text { penislengte } \\
\text { vrouwtjes }\end{array}$} & \multirow{3}{*}{$\begin{array}{c}\text { Gemiddelde } \\
\text { penislengte } \\
\text { mannetjes }\end{array}$} & \multirow{3}{*}{$\begin{array}{c}\text { Aantal } \\
\text { vrouwtjes } \\
\text { met intersex }\end{array}$} & \multicolumn{3}{|c|}{ Stadium } & $|S|$ \\
\hline & & & & & & & & & & & & & & \\
\hline RO20160203/012 & & & & & & & & & & & 1 & 2 & & \\
\hline RQ20160203/012 & $2016 / 0625$ & Alikruik & Waddenzee kustzone oost & WADDZKZNOT & $22 / 06 / 2016$ & 40 & 14 & 0.000 & 2.469 & 0 & 0 & $0 \mid$ & 0.5 & $0 .($ \\
\hline RQ20160203/013 & $2016 / 0666$ & Alikruik & Waddenzee kustzone west & WADDZKZNWT & $22 / 06 / 2016$ & 40 & 25 & 0.000 & 2.860 & 0 & 0 & 0 & $0]$ & 0. \\
\hline
\end{tabular}


Bijlage 1a. Resultaten individuele Alikruiken Waddenzee kustzone oost

\begin{tabular}{|c|c|c|c|c|c|c|c|c|c|c|c|c|}
\hline Nr. & Locatie & $\begin{array}{l}\text { DONAR } \\
\text { locatie }\end{array}$ & $\begin{array}{c}\text { Bemonster } \\
\text { datum }\end{array}$ & $\begin{array}{c}\text { Geslacht } \\
M=1, V=2, \\
p=3\end{array}$ & $\begin{array}{c}\text { Totale } \\
\text { gewicht } \\
\text { (g-1 dec) }\end{array}$ & $\begin{array}{c}\text { Lengte } \\
\text { schelp } \\
\text { (mm-1dec) }\end{array}$ & $\begin{array}{l}\text { Gewicht } \\
\text { schelp } \\
\text { (g-1 dec) }\end{array}$ & \begin{tabular}{|c|} 
Gewicht \\
vlees \\
$(\mathrm{g}-1 \mathrm{dec})$
\end{tabular} & $\begin{array}{l}\text { Penislengte } \\
\text { vrouw } \\
\text { (mm-1dec) }\end{array}$ & $\begin{array}{c}\text { Penislengte } \\
\text { man } \\
(\mathrm{mm}-1 \mathrm{dec})\end{array}$ & $\begin{array}{r}S \\
0,1,2,3\end{array}$ & m \\
\hline 1 & Waddenzee kustzone oost & WADDZKZNOT & $22 /$ jun / 2016 & 1 & 5.8 & 25.2 & 4.8 & 1.0 & & 1.3 & & \\
\hline 2 & Waddenzee kustzone oost & WADDZKZNOT & 22 / jun / 2016 & 1 & 4.8 & 25.0 & 3.9 & 0.9 & & 1.4 & & 0 \\
\hline 3 & Waddenzee kustzone oost & WADDZKZNOT & 22 / jun / 2016 & 1 & 3.9 & 22.0 & 3.2 & 0.7 & & 0.2 & & \\
\hline 4 & Waddenzee kustzone oost & WADDZKZNOT & $22 /$ jun / 2016 & 1 & 3.1 & 20.0 & 2.5 & 0.6 & & 5.6 & & \\
\hline 5 & Waddenzee kustzone oost & WADDZKZNOT & $22 /$ jun / 2016 & 2 & 4.1 & 23.3 & 3.3 & 0.8 & 0.0 & & 0 & \\
\hline 6 & Waddenzee kustzone oost & WADDZKZNOT & $22 /$ jun / 2016 & 1 & 2.6 & 18.8 & 2.1 & 0.5 & & 4.7 & & \\
\hline 7 & Waddenzee kustzone oost & WADDZKZNOT & $22 /$ jun / 2016 & 1 & 2.8 & 18.9 & 2.3 & 0.5 & & 3.4 & & \\
\hline 8 & Waddenzee kustzone oost & WADDZKZNOT & $22 /$ jun / 2016 & 1 & 3.4 & 21.5 & 2.7 & 0.7 & & 5.2 & & \\
\hline 9 & Waddenzee kustzone oost & WADDZKZNOT & $22 /$ jun / 2016 & 2 & 3.2 & 21.2 & 2.6 & 0.6 & 0.0 & & 0 & \\
\hline 10 & Waddenzee kustzone oost & WADDZKZNOT & $22 /$ jun / 2016 & 2 & 3.0 & 21.9 & 2.5 & 0.5 & 0.0 & & 0 & \\
\hline 11 & Waddenzee kustzone oost & WADDZKZNOT & $22 /$ jun / 2016 & 1 & 3.9 & 22.7 & 3.1 & 0.8 & & 0.4 & & \\
\hline 12 & Waddenzee kustzone oost & WADDZKZNOT & $22 /$ jun / 2016 & 2 & 3.0 & 19.4 & 2.4 & 0.6 & 0.0 & & 0 & \\
\hline 13 & Waddenzee kustzone oost & WADDZKZNOT & $22 /$ jun / 2016 & 1 & 3.7 & 23.3 & 3.0 & 0.7 & & 4.5 & & \\
\hline 14 & Waddenzee kustzone oost & WADDZKZNOT & $22 /$ jun / 2016 & 2 & 3.1 & 20.3 & 2.5 & 0.6 & 0.0 & & 0 & \\
\hline 15 & Waddenzee kustzone oost & WADDZKZNOT & $22 /$ jun / 2016 & 1 & 2.9 & 20.4 & 2.3 & 0.6 & & 0.3 & & \\
\hline 16 & Waddenzee kustzone oost & WADDZKZNOT & $22 /$ jun / 2016 & 1 & 3.2 & 20.6 & 2.5 & 0.7 & & 5.2 & & \\
\hline 17 & Waddenzee kustzone oost & WADDZKZNOT & $22 /$ jun / 2016 & 2 & 3.0 & 19.5 & 2.5 & 0.5 & 0.0 & & 0 & \\
\hline 18 & Waddenzee kustzone oost & WADDZKZNOT & 22 / jun / 2016 & 1 & 2.0 & 16.7 & 1.6 & 0.4 & & 3.0 & & \\
\hline 19 & Waddenzee kustzone oost & WADDZKZNOT & $22 /$ jun / 2016 & 1 & 2.2 & 18.3 & 1.9 & 0.3 & & 4.7 & & \\
\hline 20 & Waddenzee kustzone oost & WADDZKZNOT & $22 /$ jun / 2016 & 1 & 2.7 & 19.0 & 2.2 & 0.5 & & 3.8 & & \\
\hline 21 & Waddenzee kustzone oost & WADDZKZNOT & $22 /$ jun / 2016 & 1 & 2.9 & 20.2 & 2.3 & 0.6 & & 1.0 & & \\
\hline 22 & Waddenzee kustzone oost & WADDZKZNOT & 22 / jun / 2016 & 1 & 3.8 & 22.1 & 3.1 & 0.7 & & 0.0 & & \\
\hline 23 & Waddenzee kustzone oost & WADDZKZNOT & 22 / jun / 2016 & 1 & 2.5 & 19.4 & 2.1 & 0.4 & & 0.2 & & \\
\hline 24 & Waddenzee kustzone oost & WADDZKZNOT & 22 / jun / 2016 & 1 & 2.6 & 19.8 & 2.0 & 0.6 & & 5.5 & & \\
\hline 25 & Waddenzee kustzone oost & WADDZKZNOT & $22 /$ jun / 2016 & 1 & 3.7 & 21.7 & 3.0 & 0.7 & & 3.0 & & \\
\hline 26 & Waddenzee kustzone oost & WADDZKZNOT & 22 / jun / 2016 & 1 & 4.0 & 23.1 & 3.1 & 0.9 & & 0.6 & & \\
\hline 27 & Waddenzee kustzone oost & WADDZKZNOT & 22 / jun / 2016 & 2 & 2.6 & 19.7 & 2.0 & 0.6 & 0.0 & & 0 & \\
\hline 28 & Waddenzee kustzone oost & WADDZKZNOT & $22 /$ jun / 2016 & 2 & 2.5 & 19.4 & 1.9 & 0.6 & 0.0 & & 0 & \\
\hline 29 & Waddenzee kustzone oost & WADDZKZNOT & 22 / jun / 2016 & 2 & 2.3 & 18.6 & 1.8 & 0.5 & 0.0 & & 0 & \\
\hline 30 & Waddenzee kustzone oost & WADDZKZNOT & $22 /$ jun / 2016 & 2 & 2.9 & 20.3 & 2.3 & 0.6 & 0.0 & & 0 & \\
\hline 31 & Waddenzee kustzone oost & WADDZKZNOT & $22 /$ jun / 2016 & 1 & 3.6 & 22.9 & 3.0 & 0.6 & & 0.3 & & \\
\hline 32 & Waddenzee kustzone oost & WADDZKZNOT & 22 / jun / 2016 & 2 & 3.7 & 22.7 & 3.0 & 0.7 & 0.0 & & 0 & \\
\hline 33 & Waddenzee kustzone oost & WADDZKZNOT & $22 /$ jun / 2016 & 1 & 2.9 & 19.8 & 2.3 & 0.6 & & 0.4 & & \\
\hline 34 & Waddenzee kustzone oost & WADDZKZNOT & $22 /$ jun / 2016 & 2 & 3.4 & 19.5 & 2.8 & 0.6 & 0.0 & & 0 & \\
\hline 35 & Waddenzee kustzone oost & WADDZKZNOT & $22 /$ jun / 2016 & 1 & 3.0 & 21.2 & 2.4 & 0.6 & & 3.5 & & \\
\hline 36 & Waddenzee kustzone oost & WADDZKZNOT & 22 / jun / 2016 & 2 & 2.7 & 20.1 & 2.1 & 0.6 & 0.0 & & 0 & \\
\hline 37 & Waddenzee kustzone oost & WADDZKZNOT & 22 / jun / 2016 & 1 & 3.2 & 20.2 & 2.5 & 0.7 & & 0.5 & & \\
\hline 38 & Waddenzee kustzone oost & WADDZKZNOT & $22 /$ jun / 2016 & 1 & 2.9 & 20.6 & 2.3 & 0.6 & & 4.8 & & \\
\hline 39 & Waddenzee kustzone oost & WADDZKZNOT & 22 / jun / 2016 & 1 & 3.4 & 21.7 & 2.7 & 0.7 & & 0.7 & & \\
\hline 40 & Waddenzee kustzone oost & WADDZKZNOT & 22 / jun / 2016 & 2 & 2.9 & 20.6 & 2.3 & 0.6 & 0.0 & & 0 & \\
\hline
\end{tabular}


Bijlage 1b. Resultaten individuele Alikruiken Waddenzee kustzone west

\begin{tabular}{|c|c|c|c|c|c|c|c|c|c|c|c|c|}
\hline Nr. & Locatie & $\begin{array}{l}\text { DONAR } \\
\text { locatie }\end{array}$ & $\begin{array}{c}\text { Bemonster } \\
\text { datum }\end{array}$ & $\begin{array}{c}\text { Geslacht } \\
M=1, V=2, \\
p=3\end{array}$ & $\begin{array}{c}\text { Totale } \\
\text { gewicht } \\
\text { (g-1 dec) }\end{array}$ & $\begin{array}{c}\text { Lengte } \\
\text { schelp } \\
\text { (mm-1dec) }\end{array}$ & $\begin{array}{l}\text { Gewicht } \\
\text { schelp } \\
\text { (g-1 dec) }\end{array}$ & $\begin{array}{c}\text { Gewicht } \\
\text { vlees } \\
\text { (g-1dec) }\end{array}$ & $\begin{array}{l}\text { Penislengte } \\
\text { vrouw } \\
\text { (mm-1dec) }\end{array}$ & $\begin{array}{c}\text { Penislengte } \\
\text { man } \\
\text { (mm-1dec) }\end{array}$ & $\begin{array}{r}S \\
0,1,2,3\end{array}$ & ium \\
\hline 1 & Waddenzee kustzone west & WADDZKZNWT & 22 / jun / 2016 & 1 & 2.7 & 19.0 & 2.2 & 0.5 & & 1.7 & & \\
\hline 2 & Waddenzee kustzone west & WADDZKZNWT & 22 / jun / 2016 & 1 & 2.6 & 20.4 & 2.2 & 0.4 & & 1.7 & & \\
\hline 3 & Waddenzee kustzone west & WADDZKZNWT & 22 / jun / 2016 & 1 & 4.1 & 22.8 & 3.4 & 0.7 & & 0.5 & & \\
\hline 4 & Waddenzee kustzone west & WADDZKZNWT & 22 / jun / 2016 & 1 & 3.5 & 21.0 & 2.9 & 0.6 & & 5.1 & & \\
\hline 5 & Waddenzee kustzone west & WADDZKZNWT & 22 / jun / 2016 & 2 & 3.7 & 20.8 & 3.1 & 0.6 & 0.0 & & 0 & \\
\hline 6 & Waddenzee kustzone west & WADDZKZNWWT & $22 /$ jun / 2016 & 2 & 2.6 & 19.8 & 2.1 & 0.5 & 0.0 & & 0 & \\
\hline 7 & Waddenzee kustzone west & WADDZKZNWT & $22 /$ jun / 2016 & 2 & 3.9 & 22.3 & 3.2 & 0.7 & 0.0 & & 0 & \\
\hline 8 & Waddenzee kustzone west & WADDZZKZNWT & $22 /$ jun / 2016 & 2 & 3.4 & 20.5 & 2.8 & 0.6 & 0.0 & & 0 & \\
\hline 9 & Waddenzee kustzone west & WADDZKZNWT & $22 /$ jun / 2016 & 2 & 4.1 & 20.1 & 3.6 & 0.5 & 0.0 & & 0 & \\
\hline 10 & Waddenzee kustzone west & WADDZKZNWT & 22 / jun / 2016 & 1 & 4.9 & 24.5 & 3.7 & 1.2 & & 6.3 & & \\
\hline 11 & Waddenzee kustzone west & WADDZKZNWT & 22 / jun / 2016 & 2 & 3.3 & 21.2 & 2.7 & 0.6 & 0.0 & & 0 & \\
\hline 12 & Waddenzee kustzone west & WADDZZZNNWT & $22 /$ jun / 2016 & 2 & 3.6 & 20.0 & 3.1 & 0.5 & 0.0 & & 0 & \\
\hline 13 & Waddenzee kustzone west & WADDZZKZNWT & $22 /$ jun / 2016 & 2 & 4.0 & 22.1 & 3.3 & 0.7 & 0.0 & & 0 & \\
\hline 14 & Waddenzee kustzone west & WADDZKZNWT & 22 / jun / 2016 & 1 & 2.9 & 21.7 & 2.4 & 0.5 & & 3.6 & & \\
\hline 15 & Waddenzee kustzone west & WADDZKZNWT & 22 / jun / 2016 & 2 & 4.1 & 23.1 & 3.3 & 0.8 & 0.0 & & 0 & \\
\hline 16 & Waddenzee kustzone west & WADDZKZNWT & $22 /$ jun / 2016 & 2 & 4.2 & 20.7 & 3.6 & 0.6 & 0.0 & & 0 & \\
\hline 17 & Waddenzee kustzone west & WADDZKZNWWT & $22 /$ jun / 2016 & 2 & 2.6 & 18.2 & 2.1 & 0.5 & 0.0 & & 0 & \\
\hline 18 & Waddenzee kustzone west & WADDZKZNNWT & $22 /$ jun / 2016 & 1 & 3.8 & 21.4 & 3.1 & 0.7 & & 1.5 & & \\
\hline 19 & Waddenzee kustzone west & WADDZKZNWT & 22 / jun / 2016 & 2 & 3.6 & 20.3 & 3.0 & 0.6 & 0.0 & & 0 & \\
\hline 20 & Waddenzee kustzone west & WADDZKZNWT & 22 / jun / 2016 & 2 & 3.0 & 19.9 & 2.4 & 0.6 & 0.0 & & 0 & \\
\hline 21 & Waddenzee kustzone west & WADDZKZNWT & $22 /$ jun / 2016 & 2 & 3.6 & 21.7 & 3.0 & 0.6 & 0.0 & & 0 & \\
\hline 22 & Waddenzee kustzone west & WADDZKZNWT & 22 / jun / 2016 & 1 & 3.3 & 20.9 & 2.8 & 0.5 & & 5.4 & & \\
\hline 23 & Waddenzee kustzone west & WADDZKZNWT & 22 / jun / 2016 & 1 & 3.3 & 20.7 & 2.7 & 0.6 & & 4.6 & & \\
\hline 24 & Waddenzee kustzone west & WADDZKZNWT & 22 / jun / 2016 & 2 & 3.0 & 20.4 & 2.5 & 0.5 & 0.0 & & 0 & \\
\hline 25 & Waddenzee kustzone west & WADDZKZNWT & $22 /$ jun / 2016 & 2 & 3.3 & 21.7 & 2.7 & 0.6 & 0.0 & & 0 & \\
\hline 26 & Waddenzee kustzone west & WADDZKZNWT & 22 / jun / 2016 & 2 & 3.4 & 21.8 & 2.8 & 0.6 & 0.0 & & 0 & \\
\hline 27 & Waddenzee kustzone west & WADDZKZNWT & $22 /$ jun / 2016 & 2 & 2.5 & 18.6 & 2.0 & 0.5 & 0.0 & & 0 & \\
\hline 28 & Waddenzee kustzone west & WADDZKZNWT & 22 / jun / 2016 & 1 & 3.8 & 21.9 & 3.2 & 0.6 & & 2.0 & & \\
\hline 29 & Waddenzee kustzone west & WADDZKZNWT & $22 /$ jun / 2016 & 2 & 3.2 & 21.6 & 2.6 & 0.6 & 0.0 & & 0 & \\
\hline 30 & Waddenzee kustzone west & WADDZKZNWT & 22 / jun / 2016 & 2 & 3.2 & 20.6 & 2.7 & 0.5 & 0.0 & & 0 & \\
\hline 31 & Waddenzee kustzone west & WADDZKZNWT & $22 /$ jun / 2016 & 2 & 2.5 & 18.9 & 2.1 & 0.4 & 0.0 & & 0 & \\
\hline 32 & Waddenzee kustzone west & WADDZZKNNWT & $22 /$ jun / 2016 & 2 & 3.4 & 21.5 & 2.8 & 0.6 & 0.0 & & 0 & \\
\hline 33 & Waddenzee kustzone west & WADDZKZNWT & 22 / jun / 2016 & 2 & 2.6 & 19.8 & 2.1 & 0.5 & 0.0 & & 0 & \\
\hline 34 & Waddenzee kustzone west & WADDZKZNWT & $22 /$ jun / 2016 & 2 & 2.5 & 20.0 & 2.1 & 0.4 & 0.0 & & 0 & \\
\hline 35 & Waddenzee kustzone west & WADDZKZNWT & 22 / jun / 2016 & 1 & 3.0 & 20.6 & 2.5 & 0.5 & & 0.5 & & \\
\hline 36 & Waddenzee kustzone west & WADDZKZNWT & $22 /$ jun / 2016 & 1 & 3.4 & 21.9 & 2.9 & 0.5 & & 3.6 & & \\
\hline 37 & Waddenzee kustzone west & WADDZKZNWT & $22 /$ jun / 2016 & 1 & 2.7 & 19.9 & 2.2 & 0.5 & & 0.6 & & \\
\hline 38 & Waddenzee kustzone west & WADDZKZNWT & $22 /$ jun / 2016 & 1 & 2.9 & 20.8 & 2.4 & 0.5 & & 5.5 & & \\
\hline 39 & Waddenzee kustzone west & WADDZKZNWT & 22 / jun / 2016 & 2 & 3.0 & 19.5 & 2.6 & 0.4 & 0.0 & & 0 & \\
\hline 40 & Waddenzee kustzone west & WADDZKZNWT & 22 / jun / 2016 & 1 & 2.5 & 19.6 & 2.1 & 0.4 & & 0.3 & & \\
\hline
\end{tabular}


Bijlage 2. Resultaten imposex analyse Gevlochten Fuikhoorns en Purperslakken

\begin{tabular}{|c|c|c|c|c|c|c|c|c|c|c|c|c|c|c|c|c|c|c|}
\hline \multicolumn{4}{|c|}{ Imposex (Gevlochten fuikhoorns en purperslakken). } & \multirow{2}{*}{ DONAR code } & \multirow{2}{*}{ Monsterdatum } & & & & & \multirow{2}{*}{\multicolumn{7}{|c|}{ 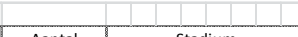 }} & \multirow{2}{*}{ VDSI } & \\
\hline RQ-nummer & LIMS-nr. & & Locatie & & & Aantal & & & & & & & & & & & & \\
\hline & & & & & & & & & & & & & & & & 4 & & \\
\hline $20160203 / 014$ & $2016 / 0707$ & Fuikhoorn & Hollands & HOLLSKZNND & $4 / 2016$ & 40 & 30 & 000 & 00 & 0 & 300 & 00 & 0 & 0 & $\begin{array}{lll}0 & 0\end{array}$ & 0 & 0.00 & 0.000000 \\
\hline 220160204/015 & $2016 / 0748$ & Fuikhoorn & e midden & HOLLS & 16 & 40 & 27 & 000 & 14.000 & 0 & & & 0 & 0 & 0.0 & 0 & 0.00 & 0.000000 \\
\hline Q2016 & $2016 / 0789$ & Fuikhoorn & Hollans & HOLL: & & 4 & 2 & & & 0 & 270 & 00 & 0 & 0 & $\begin{array}{lll}0 & 0\end{array}$ & 0 & 0.00 & 0.000000 \\
\hline Q20160204/017 & $2016 / 0830$ & Fuikhoorn & Haringv| & HARV & 16 & 37 & 18 & 0.000 & 13.579 & 0 & & 00 & 0 & 0 & 0 & 0 & 0.00 & 0.000000 \\
\hline Q20160204/018 & $2016 / 0871$ & Purperslak & Grevelir & GREVL & 16 & 4 & 2 & 0.000 & 6 & 0 & \begin{tabular}{|l|l}
24 & 0 \\
\end{tabular} & $\begin{array}{ll}0 & 0 \\
\end{array}$ & 0 & 0 & 00 & 0 & 0.00 & 0.000000 \\
\hline $220160204 / 019$ & \begin{tabular}{|l|}
$2016 / 0912$ \\
\end{tabular} & $\begin{array}{l}\text { Purperslak } \\
\end{array}$ & Oosters & & & 40 & 2 & & 4.5 & 0 & 240 & 00 & 0 & 0 & 0 & 0 & 0.00 & 0.000000 \\
\hline RQ20160204/020 & 2016/0953 & Purperslak & Westerschelde kustzone & WESTSDKZNE & $24 / 05 / 2016$ & 40 & 21 & 0.057 & 4.321 & 3 & \begin{tabular}{l|l}
18 & 2 \\
\end{tabular} & 20 & 1 & 0 & 00 & 0 & 0.14 & 0.000231 \\
\hline
\end{tabular}




\section{Bijlage 2a. Resultaten individuele Fuikhoorns Hollandse kustzone noord}

\begin{tabular}{|c|c|c|c|c|c|c|c|c|c|c|c|c|}
\hline Nr. & Locatie & $\begin{array}{l}\text { DONAR } \\
\text { locatie }\end{array}$ & $\begin{array}{c}\text { Bemonster } \\
\text { datum }\end{array}$ & $\begin{array}{c}\text { Geslacht } \\
M=1 \\
V=2 \\
p=3\end{array}$ & $\begin{array}{c}\text { Totale } \\
\text { gewicht } \\
\text { (g - } 1 \\
\text { dec) }\end{array}$ & $\begin{array}{l}\text { Lengte } \\
\text { schelp } \\
\text { (mm - } \\
1 \mathrm{dec} \text { ) }\end{array}$ & $\begin{array}{l}\text { Gewicht } \\
\text { schelp } \\
\text { (g-1 } \\
\text { dec) }\end{array}$ & $\begin{array}{c}\text { Gewicht } \\
\text { vlees } \\
(\mathrm{g}-1 \mathrm{dec})\end{array}$ & $\begin{array}{c}\text { Penislengte } \\
\text { vrouw } \\
(\mathrm{mm}-1 \mathrm{dec})\end{array}$ & $\begin{array}{c}\text { Penislengte } \\
\text { man } \\
(\mathrm{mm}-1 \mathrm{dec})\end{array}$ & $\begin{array}{r}S \\
0,1,2,3\end{array}$ & $\begin{array}{l}\text { stadium } \\
\text { 3etc a,b,c etc }\end{array}$ \\
\hline 1 & Hollandse kustzone noord & HOLLSKZNND & $05 / \mathrm{apr} / 2016$ & 2 & 3.2 & 28.5 & 1.7 & 1.5 & 0.0 & & 0 & \\
\hline 2 & Hollandse kustzone noord & HOLLSKZNND & $05 / \mathrm{apr} / 2016$ & 1 & 2.7 & 26.6 & 1.6 & 1.1 & & 19.0 & & \\
\hline 3 & Hollandse kustzone noord & HOLLSKZNND & 05 / apr / 2016 & 1 & 3.1 & 28.1 & 1.7 & 1.4 & & 14.0 & & \\
\hline 4 & Hollandse kustzone noord & HOLLSKZNND & 05 / apr / 2016 & 2 & 3.7 & 29.2 & 1.9 & 1.8 & 0.0 & & 0 & \\
\hline 5 & Hollandse kustzone noord & HOLLSKZNNND & $05 /$ apr / 2016 & 2 & 3.2 & 27.9 & 1.9 & 1.3 & 0.0 & & 0 & \\
\hline 6 & Hollandse kustzone noord & HOLLSKZNND & $05 / \mathrm{apr} / 2016$ & 1 & 3.1 & 27.3 & 2.0 & 1.1 & & 13.0 & & \\
\hline 7 & Hollandse kustzone noord & HOLLSKZNND & 05 / apr / 2016 & 2 & 3.5 & 28.6 & 2.1 & 1.4 & 0.0 & & 0 & \\
\hline 8 & Hollandse kustzone noord & HOLLSKZNND & 05 / apr / 2016 & 1 & 2.9 & 28.3 & 1.6 & 1.3 & & 13.0 & & \\
\hline 9 & Hollandse kustzone noord & HOLLSKZNND & $05 / \mathrm{apr} / 2016$ & 1 & 3.1 & 27.6 & 1.9 & 1.2 & & 13.0 & & \\
\hline 10 & Hollandse kustzone noord & HOLLSKZNND & $05 / \mathrm{apr} / 2016$ & 2 & 3.4 & 28.8 & 2.1 & 1.3 & 0.0 & & 0 & \\
\hline 11 & Hollandse kustzone noord & HOLLSKZNND & 05 / apr / 2016 & 2 & 3.5 & 29.5 & 2.0 & 1.5 & 0.0 & & 0 & \\
\hline 12 & Hollandse kustzone noord & HOLLSKZNND & 05 / apr / 2016 & 2 & 3.4 & 28.8 & 1.8 & 1.6 & 0.0 & & 0 & \\
\hline 13 & Hollandse kustzone noord & HOLLSKZNNND & 05 / apr / 2016 & 2 & 3.5 & 28.1 & 2.0 & 1.5 & 0.0 & & 0 & \\
\hline 14 & Hollandse kustzone noord & HOLLSKZNND & 05 / apr / 2016 & 2 & 3.1 & 28.4 & 1.5 & 1.6 & 0.0 & & 0 & \\
\hline 15 & Hollandse kustzone noord & HOLLSKZNND & $05 / \mathrm{apr} / 2016$ & 2 & 3.3 & 28.1 & 1.8 & 1.5 & 0.0 & & 0 & \\
\hline 16 & Hollandse kustzone noord & HOLLSKZNND & $05 /$ apr / 2016 & 2 & 3.1 & 27.8 & 1.7 & 1.4 & 0.0 & & 0 & \\
\hline 17 & Hollandse kustzone noord & HOLLSKZNND & 05 / apr / 2016 & 2 & 2.8 & 27.3 & 1.5 & 1.3 & 0.0 & & 0 & \\
\hline 18 & Hollandse kustzone noord & HOLLSKZNND & $05 / \mathrm{apr} / 2016$ & 2 & 3.0 & 27.9 & 1.6 & 1.4 & 0.0 & & 0 & \\
\hline 19 & Hollandse kustzone noord & HOLLSKZNND & $05 /$ apr / 2016 & 2 & 2.6 & 26.6 & 1.4 & 1.2 & 0.0 & & 0 & \\
\hline 20 & Hollandse kustzone noord & HOLLSKZNND & $05 / \mathrm{apr} / 2016$ & 2 & 2.8 & 26.4 & 1.4 & 1.4 & 0.0 & & 0 & \\
\hline 21 & Hollandse kustzone noord & HOLLSKZNND & 05 / apr / 2016 & 2 & 3.5 & 27.8 & 1.8 & 1.7 & 0.0 & & 0 & \\
\hline 22 & Hollandse kustzone noord & HOLLSKZNND & $05 / \mathrm{apr} / 2016$ & 2 & 3.0 & 28.4 & 1.9 & 1.1 & 0.0 & & 0 & \\
\hline 23 & Hollandse kustzone noord & HOLLSKZNND & 05 / apr / 2016 & 1 & 3.3 & 27.8 & 1.8 & 1.5 & & 15.0 & & \\
\hline 24 & Hollandse kustzone noord & HOLLSKZNND & $05 /$ apr / 2016 & 2 & 3.2 & 28.1 & 1.8 & 1.4 & 0.0 & & 0 & \\
\hline 25 & Hollandse kustzone noord & HOLLSKZNND & 05 / apr / 2016 & 1 & 3.0 & 27.6 & 2.0 & 1 & & 16.0 & & \\
\hline 26 & Hollandse kustzone noord & HOLLSKZNND & $05 / \mathrm{apr} / 2016$ & 2 & 3.1 & 27.9 & 1.8 & 1.3 & 0.0 & & 0 & \\
\hline 27 & Hollandse kustzone noord & HOLLSKZNND & 05 / apr / 2016 & 2 & 2.6 & 25.4 & 1.5 & 1.1 & 0.0 & & 0 & \\
\hline 28 & Hollandse kustzone noord & HOLLSKZNND & 05 / apr / 2016 & 2 & 3.0 & 26.7 & 1.6 & 1.4 & 0.0 & & 0 & \\
\hline 29 & Hollandse kustzone noord & HOLLSKZNND & $05 / \mathrm{apr} / 2016$ & 2 & 2.9 & 27.6 & 1.6 & 1.3 & 0.0 & & 0 & \\
\hline 30 & Hollandse kustzone noord & HOLLSKZNND & 05 / apr / 2016 & 2 & 2.7 & 26.3 & 1.7 & 1 & 0.0 & & 0 & \\
\hline 31 & Hollandse kustzone noord & HOLLSKZNND & $05 / \mathrm{apr} / 2016$ & 1 & 3.0 & 27.8 & 1.9 & 1.1 & & 15.0 & & \\
\hline 32 & Hollandse kustzone noord & HOLLSKZNND & $05 / \mathrm{apr} / 2016$ & 1 & 3.4 & 28.5 & 2.0 & 1.4 & & 16.0 & & \\
\hline 33 & Hollandse kustzone noord & HOLLSKZNND & $05 / \mathrm{apr} / 2016$ & 2 & 3.3 & 28.7 & 2.0 & 1.3 & 0.0 & & 0 & \\
\hline 34 & Hollandse kustzone noord & HOLLSKZNND & $05 /$ apr / 2016 & 2 & 2.8 & 26.6 & 1.6 & 1.2 & 0.0 & & 0 & \\
\hline 35 & Hollandse kustzone noord & HOLLSKZNND & 05 / apr / 2016 & 2 & 3.4 & 28.3 & 1.9 & 1.5 & 0.0 & & 0 & \\
\hline 36 & Hollandse kustzone noord & HOLLSKZNND & 05 / apr / 2016 & 2 & 3.2 & 27.7 & 2.0 & 1.2 & 0.0 & & 0 & \\
\hline 37 & Hollandse kustzone noord & HOLLSKZNND & 05 / apr / 2016 & 1 & 3.0 & 27.3 & 1.9 & 1.1 & & 19.0 & & \\
\hline 38 & Hollandse kustzone noord & HOLLSKZNND & 05 / apr / 2016 & 2 & 2.8 & 25.7 & 1.5 & 1.3 & 0.0 & & 0 & \\
\hline 39 & Hollandse kustzone noord & HOLLSKZNND & $05 / \mathrm{apr} / 2016$ & 2 & 2.7 & 26.2 & 1.6 & 1.1 & 0.0 & & 0 & \\
\hline 40 & Hollandse kustzone noord & HOLLSKZNND & 05 / apr / 2016 & 2 & 2.9 & 26.4 & 1.6 & 1.3 & 0.0 & & 0 & \\
\hline
\end{tabular}


Bijlage 2 b. Resultaten individuele Fuikhoorns Hollandse kustzone midden

\begin{tabular}{|c|c|c|c|c|c|c|c|c|c|c|c|c|}
\hline Nr. & Locatie & $\begin{array}{l}\text { DONAR } \\
\text { locatie }\end{array}$ & $\begin{array}{c}\text { Bemonster } \\
\text { datum }\end{array}$ & $\begin{array}{c}\text { Geslacht } \\
M=1 \\
V=2 \\
p=3\end{array}$ & $\begin{array}{c}\text { Totale } \\
\text { gewicht } \\
\text { (g-1 } \\
\text { dec) }\end{array}$ & $\begin{array}{l}\text { Lengte } \\
\text { schelp } \\
\text { (mm - } \\
1 \mathrm{dec} \text { ) }\end{array}$ & $\begin{array}{c}\text { Gewicht } \\
\text { schelp } \\
\text { (g - } 1 \\
\text { dec) }\end{array}$ & $\begin{array}{c}\text { Gewicht } \\
\text { vlees } \\
\text { (g-1dec) }\end{array}$ & $\begin{array}{c}\text { Penislengte } \\
\text { vrouw } \\
(\mathrm{mm}-1 \mathrm{dec})\end{array}$ & $\begin{array}{c}\text { Penislengte } \\
\text { man } \\
(\mathrm{mm}-1 \mathrm{dec})\end{array}$ & \multicolumn{2}{|c|}{$\begin{array}{c}\text { Stadium } \\
0,1,2,3 \text { etc } a, b, c \text { etc }\end{array}$} \\
\hline 1 & Hollandse kustzone midden & HOLLSKZNMDN & $05 / \mathrm{apr} / 2016$ & 1 & 3.0 & 27.4 & 1.6 & 1.4 & & 14.0 & & \\
\hline 2 & Hollandse kustzone midden & HOLLSKZNMDN & 05 / apr / 2016 & 2 & 3.0 & 27.6 & 1.7 & 1.3 & 0.0 & & 0 & \\
\hline 3 & Hollandse kustzone midden & HOLLSKZNMDN & 05 / apr / 2016 & 2 & 3.1 & 27.1 & 1.8 & 1.3 & 0.0 & & 0 & \\
\hline 4 & Hollandse kustzone midden & HOLLSKZNMDN & 05 / apr / 2016 & 2 & 3.7 & 29.3 & 1.7 & 2.0 & 0.0 & & 0 & \\
\hline 5 & Hollandse kustzone midden & HOLLSKZNMDN & 05 / apr / 2016 & 2 & 3.2 & 27.9 & 1.7 & 1.5 & 0.0 & & 0 & \\
\hline 6 & Hollandse kustzone midden & HOLLSKZNMDN & $05 / \mathrm{apr} / 2016$ & 2 & 2.8 & 25.6 & 1.5 & 1.3 & 0.0 & & 0 & \\
\hline 7 & Hollandse kustzone midden & HOLLSKZNMDN & $05 / a p r / 2016$ & 2 & 3.0 & 27.2 & 1.6 & 1.4 & 0.0 & & 0 & \\
\hline 8 & Hollandse kustzone midden & HOLLSKZNMDN & $05 / \mathrm{apr} / 2016$ & 2 & 3.0 & 27.3 & 1.6 & 1.4 & 0.0 & & 0 & \\
\hline 9 & Hollandse kustzone midden & HOLLSKZNMDN & $05 / \mathrm{apr} / 2016$ & 2 & 2.7 & 25.7 & 1.3 & 1.4 & 0.0 & & 0 & \\
\hline 10 & Hollandse kustzone midden & HOLLSKZNMDN & 05 / apr / 2016 & 2 & 3.0 & 27.9 & 1.5 & 1.5 & 0.0 & & 0 & \\
\hline 11 & Hollandse kustzone midden & HOLLSKZNMDN & $05 / \mathrm{apr} / 2016$ & 2 & 2.4 & 26.5 & 1.3 & 1.1 & 0.0 & & 0 & \\
\hline 12 & Hollandse kustzone midden & HOLLSKZNMDN & $05 / \mathrm{apr} / 2016$ & 2 & 2.9 & 26.9 & 1.6 & 1.3 & 0.0 & & 0 & \\
\hline 13 & Hollandse kustzone midden & HOLLSKZNMDN & 05 / apr / 2016 & 2 & 3.1 & 28.9 & 1.6 & 1.5 & 0.0 & & 0 & \\
\hline 14 & Hollandse kustzone midden & HOLLSKZNMDN & $05 / \mathrm{apr} / 2016$ & 2 & 3.2 & 27.6 & 1.6 & 1.6 & 0.0 & & 0 & \\
\hline 15 & Hollandse kustzone midden & HOLLSKZNMDN & 05 / apr / 2016 & 2 & 2.8 & 27.6 & 1.6 & 1.2 & 0.0 & & 0 & \\
\hline 16 & Hollandse kustzone midden & HOLLSKZNMDN & $05 / \mathrm{apr} / 2016$ & 2 & 2.8 & 26.7 & 1.6 & 1.2 & 0.0 & & 0 & \\
\hline 17 & Hollandse kustzone midden & HOLLSKZNMDN & 05 / apr / 2016 & 1 & 3.2 & 27.0 & 2.0 & 1.2 & & 11.0 & & \\
\hline 18 & Hollandse kustzone midden & HOLLSKZNMDN & $05 / \mathrm{apr} / 2016$ & 1 & 2.9 & 26.5 & 1.8 & 1.1 & & 13.0 & & \\
\hline 19 & Hollandse kustzone midden & HOLLSKZNMDN & 05 / apr / 2016 & 1 & 2.4 & 25.8 & 1.4 & 1.0 & & 14.0 & & \\
\hline 20 & Hollandse kustzone midden & HOLLSKZNMDN & $05 / \mathrm{apr} / 2016$ & 2 & 3.0 & 28.1 & 1.4 & 1.6 & 0.0 & & 0 & \\
\hline 21 & Hollandse kustzone midden & HOLLSKZNMDN & $05 / \mathrm{apr} / 2016$ & 2 & 2.6 & 26.5 & 1.5 & 1.1 & 0.0 & & 0 & \\
\hline 22 & Hollandse kustzone midden & HOLLSKZNMDN & $05 / \mathrm{apr} / 2016$ & 2 & 3.6 & 28.7 & 2.1 & 1.5 & 0.0 & & 0 & \\
\hline 23 & Hollandse kustzone midden & HOLLSKZNMDN & $05 / \mathrm{apr} / 2016$ & 1 & 2.0 & 24.6 & 1.1 & 0.9 & & 10.0 & & \\
\hline 24 & Hollandse kustzone midden & HOLLSKZNMDN & $05 / \mathrm{apr} / 2016$ & 2 & 2.8 & 28.1 & 1.5 & 1.3 & 0.0 & & 0 & \\
\hline 25 & Hollandse kustzone midden & HOLLSKZNMDN & 05 / apr / 2016 & 2 & 3.0 & 26.9 & 1.4 & 1.6 & 0.0 & & 0 & \\
\hline 26 & Hollandse kustzone midden & HOLLSKZNMDN & $05 / \mathrm{apr} / 2016$ & 1 & 3.0 & 27.6 & 1.6 & 1.4 & & 14.0 & & \\
\hline 27 & Hollandse kustzone midden & HOLLSKZNMDN & 05 / apr / 2016 & 1 & 3.2 & 28.2 & 1.7 & 1.5 & & 17.0 & & \\
\hline 28 & Hollandse kustzone midden & HOLLSKZNMDN & $05 / \mathrm{apr} / 2016$ & 2 & 3.1 & 27.4 & 1.7 & 1.4 & 0.0 & & 0 & \\
\hline 29 & Hollandse kustzone midden & HOLLSKZNMDN & 05 / apr / 2016 & 1 & 2.4 & 25.7 & 1.4 & 1.0 & & 16.0 & & \\
\hline 30 & Hollandse kustzone midden & HOLLSKZNMDN & 05 / apr / 2016 & 2 & 3.0 & 27.9 & 1.8 & 1.2 & 0.0 & & 0 & \\
\hline 31 & Hollandse kustzone midden & HOLLSKZNMDN & $05 / \mathrm{apr} / 2016$ & 2 & 3.2 & 28.1 & 1.5 & 1.7 & 0.0 & & 0 & \\
\hline 32 & Hollandse kustzone midden & HOLLSKZNMDN & $05 / \mathrm{apr} / 2016$ & 2 & 2.8 & 25.2 & 1.4 & 1.4 & 0.0 & & 0 & \\
\hline 33 & Hollandse kustzone midden & HOLLSKZNMDN & 05 / apr / 2016 & 2 & 3.3 & 26.7 & 1.6 & 1.7 & 0.0 & & 0 & \\
\hline 34 & Hollandse kustzone midden & HOLLSKZNMDN & $05 / \mathrm{apr} / 2016$ & 2 & 3.3 & 28.2 & 1.8 & 1.5 & 0.0 & & 0 & \\
\hline 35 & Hollandse kustzone midden & HOLLSKZNMDN & $05 / \mathrm{apr} / 2016$ & 1 & 2.2 & 25.2 & 1.2 & 1.0 & & 15.0 & & \\
\hline 36 & Hollandse kustzone midden & HOLLSKZNMDN & $05 / \mathrm{apr} / 2016$ & 1 & 2.3 & 25.0 & 1.2 & 1.1 & & 14.0 & & \\
\hline 37 & Hollandse kustzone midden & HOLLSKZNMDN & 05 / apr / 2016 & 1 & 2.4 & 25.9 & 1.4 & 1.0 & & 15.0 & & \\
\hline 38 & Hollandse kustzone midden & HOLLSKZNMDN & $05 / \mathrm{apr} / 2016$ & 1 & 3.0 & 27.6 & 1.8 & 1.2 & & 13.0 & & \\
\hline 39 & Hollandse kustzone midden & HOLLSKZNMDN & 05 / apr / 2016 & 1 & 2.2 & 24.9 & 1.1 & 1.1 & & 16.0 & & \\
\hline 40 & Hollandse kustzone midden & HOLLSKZNMDN & $05 / \mathrm{apr} / 2016$ & 2 & 2.8 & 27.4 & 1.3 & 1.5 & 0.0 & & 0 & \\
\hline
\end{tabular}




\section{Bijlage 2c. Resultaten individuele Fuikhoorns Hollandse kustzone zuid}

\begin{tabular}{|c|c|c|c|c|c|c|c|c|c|c|c|c|}
\hline Nr. & Locatie & $\begin{array}{l}\text { DONAR } \\
\text { locatie }\end{array}$ & $\begin{array}{c}\text { Bemonster } \\
\text { datum }\end{array}$ & $\begin{array}{c}\text { Geslacht } \\
M=1, \\
V=2, \\
p=3\end{array}$ & $\begin{array}{c}\text { Totale } \\
\text { gewicht } \\
\text { (g-1 } \\
\text { dec) }\end{array}$ & $\begin{array}{l}\text { Lengte } \\
\text { schelp } \\
\text { (mm - } \\
1 \mathrm{dec})\end{array}$ & $\begin{array}{l}\text { Gewicht } \\
\text { schelp } \\
(\mathrm{g}-1 \\
\mathrm{dec})\end{array}$ & $\begin{array}{c}\text { Gewicht } \\
\text { vlees } \\
\text { (g-1dec) }\end{array}$ & $\begin{array}{c}\text { Penislengte } \\
\text { vrouw } \\
(\mathrm{mm}-1 \mathrm{dec})\end{array}$ & $\begin{array}{c}\text { Penislengte } \\
\text { man } \\
(\mathrm{mm}-1 \mathrm{dec})\end{array}$ & $\begin{array}{r}S t \\
0,1,2,3\end{array}$ & $\begin{array}{l}\text { Stadium } \\
3 \text { etc a,b,c etc }\end{array}$ \\
\hline 1 & Hollandse kustzone zuid & HOLLSKZNZD & 04/apr / 2016 & 2 & 3.5 & 28.8 & 2.0 & 1.5 & 0.0 & & 0 & \\
\hline 2 & Hollandse kustzone zuid & HOLLSKZNZD & 04 / apr / 2016 & 1 & 2.5 & 26.4 & 1.4 & 1.1 & & 14.5 & & \\
\hline 3 & Hollandse kustzone zuid & HOLLSKZNZD & $04 / \mathrm{apr} / 2016$ & 2 & 3.3 & 28.0 & 2.0 & 1.3 & 0.0 & & 0 & \\
\hline 4 & Hollandse kustzone zuid & HOLLSKZNZD & 04 / apr / 2016 & 1 & 2.8 & 27.1 & 1.6 & 1.2 & & 16.0 & & \\
\hline 5 & Hollandse kustzone zuid & HOLLSKZNZD & 04 / apr / 2016 & 1 & 2.6 & 26.4 & 1.4 & 1.2 & & 17.0 & & \\
\hline 6 & Hollandse kustzone zuid & HOLLSKZNZD & 04 / apr / 2016 & 2 & 2.7 & 26.3 & 1.5 & 1.2 & 0.0 & & 0 & \\
\hline 7 & Hollandse kustzone zuid & HOLLSKZNZD & 04 / apr / 2016 & 2 & 3.0 & 27.0 & 1.7 & 1.3 & 0.0 & & 0 & \\
\hline 8 & Hollandse kustzone zuid & HOLLSKZNZD & 04 / apr / 2016 & 2 & 2.6 & 25.4 & 1.5 & 1.1 & 0.0 & & 0 & \\
\hline 9 & Hollandse kustzone zuid & HOLLSKZNZD & 04 / apr / 2016 & 1 & 2.6 & 26.5 & 1.7 & 0.9 & & 17.0 & & \\
\hline 10 & Hollandse kustzone zuid & HOLLSKZNZD & $04 / \mathrm{apr} / 2016$ & 2 & 2.9 & 26.4 & 1.7 & 1.2 & 0.0 & & 0 & \\
\hline 11 & Hollandse kustzone zuid & HOLLSKZNZD & 04 / apr / 2016 & 2 & 2.7 & 27.0 & 1.3 & 1.4 & 0.0 & & 0 & \\
\hline 12 & Hollandse kustzone zuid & HOLLSKZNZD & 04 / apr / 2016 & 2 & 2.8 & 26.4 & 1.4 & 1.4 & 0.0 & & 0 & \\
\hline 13 & Hollandse kustzone zuid & HOLLSKZNZD & 04 / apr / 2016 & 2 & 3.6 & 27.9 & 2.0 & 1.6 & 0.0 & & 0 & \\
\hline 14 & Hollandse kustzone zuid & HOLLSKZNZD & 04 / apr / 2016 & 1 & 2.8 & 26.7 & 1.6 & 1.2 & & 18.0 & & \\
\hline 15 & Hollandse kustzone zuid & HOLLSKZNZD & 04 / apr / 2016 & 2 & 3.0 & 27.6 & 1.5 & 1.5 & 0.0 & & 0 & \\
\hline 16 & Hollandse kustzone zuid & HOLLSKZNZD & 04 / apr / 2016 & 2 & 3.3 & 28.4 & 2.0 & 1.3 & 0.0 & & 0 & \\
\hline 17 & Hollandse kustzone zuid & HOLLSKZNZD & 04 / apr / 2016 & 1 & 2.5 & 26.2 & 1.5 & 1.0 & & 15.0 & & \\
\hline 18 & Hollandse kustzone zuid & HOLLSKZNZD & 04 / apr / 2016 & 2 & 3.3 & 27.8 & 1.7 & 1.6 & 0.0 & & 0 & \\
\hline 19 & Hollandse kustzone zuid & HOLLSKZNZD & $04 /$ apr / 2016 & 1 & 2.6 & 26.1 & 1.6 & 1.0 & & 12.0 & & \\
\hline 20 & Hollandse kustzone zuid & HOLLSKZNZD & 04 / apr / 2016 & 2 & 2.7 & 26.3 & 1.6 & 1.1 & 0.0 & & 0 & \\
\hline 21 & Hollandse kustzone zuid & HOLLSKZNZD & 04 / apr / 2016 & 2 & 2.8 & 25.9 & 1.6 & 1.2 & 0.0 & & 0 & \\
\hline 22 & Hollandse kustzone zuid & HOLLSKZNZD & 04 / apr / 2016 & 2 & 3.3 & 28.1 & 1.7 & 1.6 & 0.0 & & 0 & \\
\hline 23 & Hollandse kustzone zuid & HOLLSKZNZD & $04 /$ apr / 2016 & 1 & 2.5 & 25.8 & 1.5 & 1.0 & & 18.0 & & \\
\hline 24 & Hollandse kustzone zuid & HOLLSKZNZD & 04 / apr / 2016 & 1 & 2.4 & 25.3 & 1.4 & 1.0 & & 19.0 & & \\
\hline 25 & Hollandse kustzone zuid & HOLLSKZNZD & 04 / apr / 2016 & 2 & 2.7 & 25.7 & 1.7 & 1.0 & 0.0 & & 0 & \\
\hline 26 & Hollandse kustzone zuid & HOLLSKZNZD & 04 / apr / 2016 & 1 & 2.6 & 26.2 & 1.6 & 1.0 & & 16.0 & & \\
\hline 27 & Hollandse kustzone zuid & HOLLSKZNZD & 04 / apr / 2016 & 1 & 2.3 & 26.0 & 1.2 & 1.1 & & 15.0 & & \\
\hline 28 & Hollandse kustzone zuid & HOLLSKZNZD & 04 / apr / 2016 & 1 & 2.6 & 26.6 & 1.4 & 1.2 & & 13.0 & & \\
\hline 29 & Hollandse kustzone zuid & HOLLSKZNZD & 04 / apr / 2016 & 1 & 2.5 & 24.3 & 1.4 & 1.1 & & 16.0 & & \\
\hline 30 & Hollandse kustzone zuid & HOLLSKZNZD & 04 / apr / 2016 & 2 & 3.1 & 27.1 & 1.7 & 1.4 & 0.0 & & 0 & \\
\hline 31 & Hollandse kustzone zuid & HOLLSKZNZD & 04 / apr / 2016 & 2 & 3 & 27.0 & 1.7 & 1.3 & 0.0 & & 0 & \\
\hline 32 & Hollandse kustzone zuid & HOLLSKZNZD & 04 / apr / 2016 & 2 & 2.8 & 26.1 & 1.7 & 1.1 & 0.0 & & 0 & \\
\hline 33 & Hollandse kustzone zuid & HOLLSKZNZD & 04 / apr / 2016 & 2 & 2.9 & 27.4 & 1.5 & 1.4 & 0.0 & & 0 & \\
\hline 34 & Hollandse kustzone zuid & HOLLSKZNZD & 04 / apr / 2016 & 2 & 3.6 & 30.0 & 2.1 & 1.5 & 0.0 & & 0 & \\
\hline 35 & Hollandse kustzone zuid & HOLLSKZNZD & 04 / apr / 2016 & 2 & 2.7 & 26.5 & 1.5 & 1.2 & 0.0 & & 0 & \\
\hline 36 & Hollandse kustzone zuid & HOLLSKZNZD & 04 / apr / 2016 & 2 & 2.9 & 25.8 & 1.5 & 1.4 & 0.0 & & 0 & \\
\hline 37 & Hollandse kustzone zuid & HOLLSKZNZD & 04 / apr / 2016 & 2 & 2.7 & 27.8 & 1.5 & 1.2 & 0.0 & & 0 & \\
\hline 38 & Hollandse kustzone zuid & HOLLSKZNZD & 04 / apr / 2016 & 2 & 2.6 & 25.3 & 1.4 & 1.2 & 0.0 & & 0 & \\
\hline 39 & Hollandse kustzone zuid & HOLLSKZNZD & $04 /$ apr / 2016 & 2 & 3.4 & 28.6 & 1.8 & 1.6 & 0.0 & & 0 & \\
\hline 40 & Hollandse kustzone zuid & HOLLSKZNZD & 04 / apr / 2016 & 2 & 3 & 26.9 & 1.6 & 1.4 & 0.0 & & 0 & \\
\hline
\end{tabular}




\section{Bijlage 2d. Resultaten individuele Fuikhoorns Haringvliet kustzone}

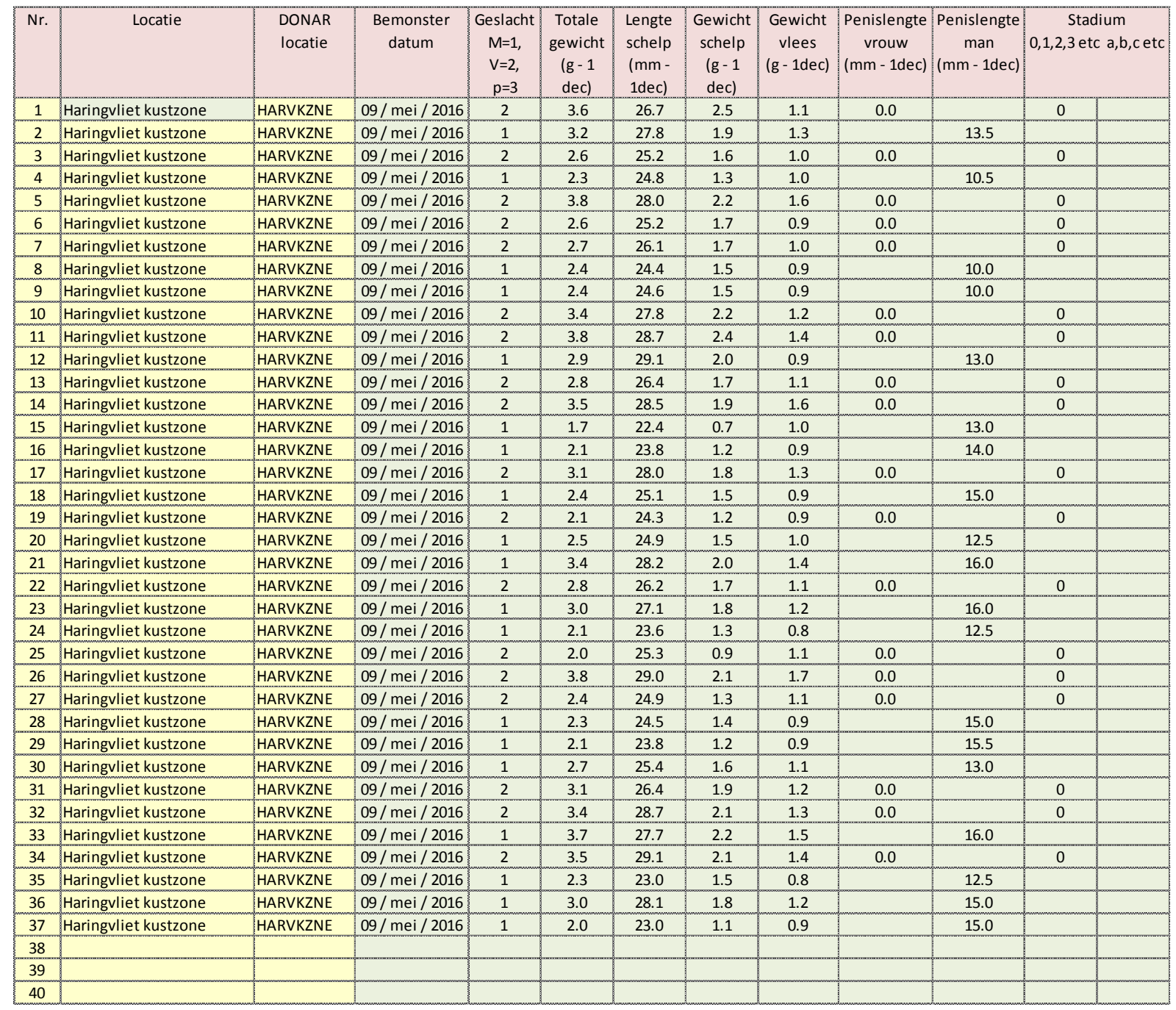


Bijlage 2e. Resultaten individuele Purperslakken Grevelingen kustzone

\begin{tabular}{|c|c|c|c|c|c|c|c|c|c|c|c|c|}
\hline Nr. & Locatie & $\begin{array}{l}\text { DONAR } \\
\text { locatie }\end{array}$ & $\begin{array}{c}\text { Bemonster } \\
\text { datum }\end{array}$ & $\begin{array}{c}\text { Geslacht } \\
M=1 \\
V=2, \\
p=3\end{array}$ & $\begin{array}{c}\text { Totale } \\
\text { gewicht } \\
\text { (g-1 dec) }\end{array}$ & $\begin{array}{l}\text { Lengte } \\
\text { schelp } \\
\text { (mm - } \\
1 \mathrm{dec} \text { ) }\end{array}$ & $\begin{array}{l}\text { Gewicht } \\
\text { schelp } \\
\text { (g-1dec) }\end{array}$ & $\begin{array}{l}\text { Gewicht } \\
\text { vlees } \\
\text { (g-1dec) }\end{array}$ & $\begin{array}{l}\text { Penislengte } \\
\text { vrouw } \\
\text { (mm - 1dec) }\end{array}$ & $\left.\begin{array}{c}\text { Penislengte } \\
\text { man } \\
(\mathrm{mm}-1 \mathrm{dec})\end{array}\right)$ & $\begin{array}{r}\text { St } \\
0,1,2,3\end{array}$ & $\begin{array}{l}\text { adium } \\
\text { tc } a, b, c \text { etc }\end{array}$ \\
\hline 1 & Grevelingen kustzone & GREVLGKZNE & 24 / mei / 2016 & 2 & 4.5 & 32.0 & 3.0 & 1.5 & 0.0 & & 0 & \\
\hline 2 & Grevelingen kustzone & GREVLGKZNE & 24 / mei / 2016 & 2 & 3.5 & 28.6 & 2.4 & 1.1 & 0.0 & & 0 & \\
\hline 3 & Grevelingen kustzone & GREVLGKZNE & $24 / \mathrm{mei} / 2016$ & 2 & 3.5 & 29.9 & 2.4 & 1.1 & 0.0 & & 0 & \\
\hline 4 & Grevelingen kustzone & GREVLGKZNE & 24/mei / 2016 & 1 & 5.0 & 31.2 & 3.6 & 1.4 & & 4.9 & & \\
\hline 5 & Grevelingen kustzone & GREVLGKZNE & $24 / \mathrm{mei} / 2016$ & 2 & 5.7 & 32.7 & 4.0 & 1.7 & 0.0 & & 0 & \\
\hline 6 & Grevelingen kustzone & GREVLGKZNE & 24 / mei / 2016 & 1 & 4.7 & 31.4 & 3.3 & 1.4 & & 4.5 & & \\
\hline 7 & Grevelingen kustzone & GREVLGKZNE & 24 / mei / 2016 & 1 & 4.2 & 30.7 & 2.9 & 1.3 & & 4.8 & & \\
\hline 8 & Grevelingen kustzone & GREVLGKZNE & $24 / \mathrm{mei} / 2016$ & 1 & 3.4 & 26.9 & 2.3 & 1.1 & & 4.6 & & \\
\hline 9 & Grevelingen kustzone & GREVLGKZNE & $24 / \mathrm{mei} / 2016$ & 1 & 4.0 & 28.7 & 2.9 & 1.1 & & 5.5 & & \\
\hline 10 & Grevelingen kustzone & GREVLGKZNE & $24 / \mathrm{mei} / 2016$ & 2 & 4.4 & 29.8 & 2.9 & 1.5 & 0.0 & & 0 & \\
\hline 11 & Grevelingen kustzone & GREVLGKZNE & $24 / \mathrm{mei} / 2016$ & 2 & 3.1 & 27.2 & 2.3 & 0.8 & 0.0 & & 0 & \\
\hline 12 & Grevelingen kustzone & GREVLGKZNE & $24 / \mathrm{mei} / 2016$ & 2 & 4.1 & 31.2 & 2.6 & 1.5 & 0.0 & & 0 & \\
\hline 13 & Grevelingen kustzone & GREVLGKZNE & 24 / mei / 2016 & 1 & 3.9 & 28.1 & 2.7 & 1.2 & & 5.0 & & \\
\hline 14 & Grevelingen kustzone & GREVLGKZNE & 24 / mei / 2016 & 2 & 3.4 & 28.1 & 2.4 & 1.0 & 0.0 & & 0 & \\
\hline 15 & Grevelingen kustzone & GREVLGKZNE & $24 / \mathrm{mei} / 2016$ & 2 & 3.1 & 28.4 & 2.1 & 1.0 & 0.0 & & 0 & \\
\hline 16 & Grevelingen kustzone & GREVLGKZNE & 24 / mei / 2016 & 1 & 3.1 & 28.0 & 2.4 & 0.7 & & 4.7 & & \\
\hline 17 & Grevelingen kustzone & GREVLGKZNE & $24 / \mathrm{mei} / 2016$ & 2 & 3.2 & 27.1 & 2.3 & 0.9 & 0.0 & & 0 & \\
\hline 18 & Grevelingen kustzone & GREVLGKZNE & 24 / mei / 2016 & 2 & 3.2 & 29.0 & 2.1 & 1.1 & 0.0 & & 0 & \\
\hline 19 & Grevelingen kustzone & GREVLGKZNE & $24 / \mathrm{mei} / 2016$ & 2 & 3.6 & 28.0 & 2.4 & 1.2 & 0.0 & & 0 & \\
\hline 20 & Grevelingen kustzone & GREVLGKZNE & 24 / mei / 2016 & 1 & 4.0 & 28.6 & 2.8 & 1.2 & & 4.9 & & \\
\hline 21 & Grevelingen kustzone & GREVLGKZNE & $24 / \mathrm{mei} / 2016$ & 2 & 4.0 & 29.8 & 2.8 & 1.2 & 0.0 & & 0 & \\
\hline 22 & Grevelingen kustzone & GREVLGKZNE & 24 / mei / 2016 & 2 & 3.2 & 26.4 & 2.1 & 1.1 & 0.0 & & 0 & \\
\hline 23 & Grevelingen kustzone & GREVLGKZNE & $24 / \mathrm{mei} / 2016$ & 2 & 5.6 & 28.7 & 4.1 & 1.5 & 0.0 & & 0 & \\
\hline 24 & Grevelingen kustzone & GREVLGKZNE & $24 / \mathrm{mei} / 2016$ & 2 & 4.7 & 30.9 & 3.2 & 1.5 & 0.0 & & 0 & \\
\hline 25 & Grevelingen kustzone & GREVLGKZNE & $24 / \mathrm{mei} / 2016$ & 1 & 2.9 & 28.0 & 1.8 & 1.1 & & 4.5 & & \\
\hline 26 & Grevelingen kustzone & GREVLGKZNE & 24 / mei / 2016 & 2 & 3.2 & 30.7 & 2.2 & 1.0 & 0.0 & & 0 & \\
\hline 27 & Grevelingen kustzone & GREVLGKZNE & 24 / mei / 2016 & 2 & 3.4 & 27.1 & 2.6 & 0.8 & 0.0 & & 0 & \\
\hline 28 & Grevelingen kustzone & GREVLGKZNE & 24 / mei / 2016 & 2 & 4.0 & 26.8 & 3.2 & 0.8 & 0.0 & & 0 & \\
\hline 29 & Grevelingen kustzone & GREVLGKZNE & $24 / \mathrm{mei} / 2016$ & 2 & 2.6 & 27.6 & 1.7 & 0.9 & 0.0 & & 0 & \\
\hline 30 & Grevelingen kustzone & GREVLGKZNE & $24 / \mathrm{mei} / 2016$ & 1 & 4.2 & 29.1 & 3.2 & 1.0 & & 3.4 & & \\
\hline 31 & Grevelingen kustzone & GREVLGKZNE & $24 / \mathrm{mei} / 2016$ & 2 & 2.6 & 25.9 & 1.6 & 1.0 & 0.0 & & 0 & \\
\hline 32 & Grevelingen kustzone & GREVLGKZNE & $24 / \mathrm{mei} / 2016$ & 1 & 2.8 & 25.8 & 1.9 & 0.9 & & 4.2 & & \\
\hline 33 & Grevelingen kustzone & GREVLGKZNE & $24 / \mathrm{mei} / 2016$ & 1 & 3.2 & 26.3 & 2.5 & 0.7 & & 3.6 & & \\
\hline 34 & Grevelingen kustzone & GREVLGKZNE & $24 / \mathrm{mei} / 2016$ & 2 & 4.2 & 27.3 & 3.1 & 1.1 & 0.0 & & 0 & \\
\hline 35 & Grevelingen kustzone & GREVLGKZNE & $24 / \mathrm{mei} / 2016$ & 1 & 3.2 & 27.3 & 2.6 & 0.6 & & 5.2 & & \\
\hline 36 & Grevelingen kustzone & GREVLGKZNE & $24 / \mathrm{mei} / 2016$ & 1 & 3.5 & 25.8 & 2.6 & 0.9 & & 5.2 & & \\
\hline 37 & Grevelingen kustzone & GREVLGKZNE & $24 / \mathrm{mei} / 2016$ & 1 & 3.1 & 26.3 & 2.2 & 0.9 & & 4.5 & & \\
\hline 38 & Grevelingen kustzone & GREVLGKZNE & $24 / \mathrm{mei} / 2016$ & 2 & 3.2 & 24.1 & 2.4 & 0.8 & 0.0 & & 0 & \\
\hline 39 & Grevelingen kustzone & GREVLGKZNE & 24 / mei / 2016 & 1 & 2.9 & 25.3 & 1.9 & 1.0 & & 4.2 & & \\
\hline 40 & Grevelingen kustzone & GREVLGKZNE & 24 / mei / 2016 & 2 & 3.1 & 27.3 & 2.1 & 1.0 & 0.0 & & 0 & \\
\hline
\end{tabular}




\section{Bijlage 2f. Resultaten individuele Purperslakken Oosterschelde kustzone}

\begin{tabular}{|c|c|c|c|c|c|c|c|c|c|c|c|c|}
\hline Nr. & Locatie & $\begin{array}{l}\text { DONAR } \\
\text { locatie }\end{array}$ & $\begin{array}{c}\text { Bemonster } \\
\text { datum }\end{array}$ & $\begin{array}{c}\text { Geslacht } \\
M=1 \\
V=2 \\
p=3\end{array}$ & $\begin{array}{c}\text { Totale } \\
\text { gewicht } \\
(\mathrm{g}-1 \\
\mathrm{dec})\end{array}$ & $\begin{array}{l}\text { Lengte } \\
\text { schelp } \\
\text { (mm - } \\
1 \mathrm{dec})\end{array}$ & $\begin{array}{c}\text { Gewicht } \\
\text { schelp } \\
(\mathrm{g}-1 \\
\text { dec) }\end{array}$ & $\begin{array}{c}\text { Gewicht } \\
\text { vlees } \\
\text { (g-1dec) }\end{array}$ & $\begin{array}{c}\text { Penislengte } \\
\text { vrouw } \\
(\mathrm{mm}-1 \mathrm{dec})\end{array}$ & $\left|\begin{array}{c}\text { Penislengte } \\
\text { man } \\
(\mathrm{mm}-1 \mathrm{dec})\end{array}\right|$ & $\begin{array}{r}S \\
0,1,2,3\end{array}$ & $\begin{array}{l}\text { Stadium } \\
\text { etc a,b,c etc }\end{array}$ \\
\hline 1 & Oosterschelde kustzone & OOSTSDKZNE & 24 / $\mathrm{mei} / 2016$ & 1 & 4.4 & 31.1 & 3.0 & 1.4 & & 5.4 & & \\
\hline 2 & Oosterschelde kustzone & OOSTSDKZNE & $24 / \mathrm{mei} / 2016$ & 1 & 4.6 & 29.8 & 3.6 & 1.0 & & 5.2 & & \\
\hline 3 & Oosterschelde kustzone & OOSTSDKZNE & 24 / mei / 2016 & 2 & 4.3 & 30.4 & 3.1 & 1.2 & 0.0 & & 0 & \\
\hline 4 & Oosterschelde kustzone & OOSTSDKZNE & 24 / mei / 2016 & 1 & 4.7 & 30.1 & 3.8 & 0.9 & & 4.5 & & \\
\hline 5 & Oosterschelde kustzone & OOSTSDKZNE & 24 / mei / 2016 & 2 & 3.4 & 28.3 & 2.4 & 1.0 & 0.0 & & 0 & \\
\hline 6 & Oosterschelde kustzone & OOSTSDKZNE & $24 / \mathrm{mei} / 2016$ & 2 & 4.1 & 28.6 & 3.0 & 1.1 & 0.0 & & 0 & \\
\hline 7 & Oosterschelde kustzone & OOSTSDKZNE & 24 / $\mathrm{mei} / 2016$ & 1 & 3.0 & 25.1 & 2.2 & 0.8 & & 4.4 & & \\
\hline 8 & Oosterschelde kustzone & OOSTSDKZNE & 24 / mei / 2016 & 1 & 5.2 & 32.1 & 3.7 & 1.5 & & 4.0 & & \\
\hline 9 & Oosterschelde kustzone & OOSTSDKZNE & 24 / mei / 2016 & 2 & 4.6 & 30.4 & 3.6 & 1.0 & 0.0 & & 0 & \\
\hline 10 & Oosterschelde kustzone & OOSTSDKZNE & $24 / \mathrm{mei} / 2016$ & 2 & 5.1 & 31.5 & 3.7 & 1.4 & 0.0 & & 0 & \\
\hline 11 & Oosterschelde kustzone & OOSTSDKZNE & 24 / mei / 2016 & 2 & 5.6 & 31.9 & 4.3 & 1.3 & 0.0 & & 0 & \\
\hline 12 & Oosterschelde kustzone & OOSTSDKZNE & 24 / mei / 2016 & 1 & 4.8 & 30.7 & 3.9 & 0.9 & & 4.5 & & \\
\hline 13 & Oosterschelde kustzone & OOSTSDKZNE & 24 / mei / 2016 & 2 & 4.8 & 33.5 & 3.5 & 1.3 & 0.0 & & 0 & \\
\hline 14 & Oosterschelde kustzone & OOSTSDKZNE & 24 / mei / 2016 & 2 & 4.0 & 29.0 & 3.1 & 0.9 & 0.0 & & 0 & \\
\hline 15 & Oosterschelde kustzone & OOSTSDKZNE & $24 / \mathrm{mei} / 2016$ & 2 & 4.2 & 29.4 & 3.1 & 1.1 & 0.0 & & 0 & \\
\hline 16 & Oosterschelde kustzone & OOSTSDKZNE & 24 / mei / 2016 & 1 & 4.8 & 28.9 & 3.9 & 0.9 & & 4.8 & & \\
\hline 17 & Oosterschelde kustzone & OOSTSDKZNE & 24 / mei / 2016 & 1 & 3.2 & 28.8 & 2.3 & 0.9 & & 5.2 & & \\
\hline 18 & Oosterschelde kustzone & OOSTSDKZNE & 24 / mei / 2016 & 1 & 3.5 & 28.8 & 2.6 & 0.9 & & 4.4 & & \\
\hline 19 & Oosterschelde kustzone & OOSTSDKZNE & $24 / \mathrm{mei} / 2016$ & 2 & 4.0 & 27.8 & 2.9 & 1.1 & 0.0 & & 0 & \\
\hline 20 & Oosterschelde kustzone & OOSTSDKZNE & 24 / mei / 2016 & 2 & 3.8 & 28.3 & 3.0 & 0.8 & 0.0 & & 0 & \\
\hline 21 & Oosterschelde kustzone & OOSTSDKZNE & 24 / $\mathrm{mei} / 2016$ & 2 & 4.4 & 29.1 & 3.4 & 1.0 & 0.0 & & 0 & \\
\hline 22 & Oosterschelde kustzone & OOSTSDKZNE & 24 / mei / 2016 & 2 & 3.8 & 29.1 & 3.0 & 0.8 & 0.0 & & 0 & \\
\hline 23 & Oosterschelde kustzone & OOSTSDKZNE & 24 / mei / 2016 & 2 & 4.0 & 27.5 & 3.0 & 1.0 & 0.0 & & 0 & \\
\hline 24 & Oosterschelde kustzone & OOSTSDKZNE & 24 / mei / 2016 & 2 & 4.0 & 28.2 & 3.0 & 1.0 & 0.0 & & 0 & \\
\hline 25 & Oosterschelde kustzone & OOSTSDKZNE & 24 / mei / 2016 & 2 & 3.2 & 27.3 & 2.7 & 0.5 & 0.0 & & 0 & \\
\hline 26 & Oosterschelde kustzone & OOSTSDKZNE & 24 / mei / 2016 & 1 & 4.0 & 28.3 & 3.1 & 0.9 & & 4.2 & & \\
\hline 27 & Oosterschelde kustzone & OOSTSDKZNE & 24 / mei / 2016 & 1 & 4.4 & 30.7 & 3.4 & 1.0 & & 4.8 & & \\
\hline 28 & Oosterschelde kustzone & OOSTSDKZNE & $24 / \mathrm{mei} / 2016$ & 2 & 4.2 & 27.2 & 3.3 & 0.9 & 0.0 & & 0 & \\
\hline 29 & Oosterschelde kustzone & OOSTSDKZNE & $24 / \mathrm{mei} / 2016$ & 2 & 3.7 & 29.8 & 2.8 & 0.9 & 0.0 & & 0 & \\
\hline 30 & Oosterschelde kustzone & OOSTSDKZNE & 24 / mei / 2016 & 2 & 3.8 & 26.1 & 2.9 & 0.9 & 0.0 & & 0 & \\
\hline 31 & Oosterschelde kustzone & OOSTSDKZNE & 24 / mei / 2016 & 2 & 3.5 & 27.2 & 2.8 & 0.7 & 0.0 & & 0 & \\
\hline 32 & Oosterschelde kustzone & OOSTSDKZNE & 24 / mei / 2016 & 1 & 3.1 & 26.1 & 2.5 & 0.6 & & 4.6 & & \\
\hline 33 & Oosterschelde kustzone & OOSTSDKZNE & 24 / $\mathrm{mei} / 2016$ & 2 & 3.6 & 28.2 & 2.7 & 0.9 & 0.0 & & 0 & \\
\hline 34 & Oosterschelde kustzone & OOSTSDKZNE & 24 / mei / 2016 & 2 & 3.6 & 26.4 & 3.0 & 0.6 & 0.0 & & 0 & \\
\hline 35 & Oosterschelde kustzone & OOSTSDKZNE & 24 / mei / 2016 & 1 & 3.5 & 26.6 & 2.7 & 0.8 & & 4.2 & & \\
\hline 36 & Oosterschelde kustzone & OOSTSDKZNE & $24 / \mathrm{mei} / 2016$ & 2 & 3.2 & 26.6 & 2.5 & 0.7 & 0.0 & & 0 & \\
\hline 37 & Oosterschelde kustzone & OOSTSDKZNE & 24 / mei / 2016 & 1 & 3.6 & 26.8 & 2.8 & 0.8 & & 3.9 & & \\
\hline 38 & Oosterschelde kustzone & OOSTSDKZNE & 24 / mei / 2016 & 1 & 3.2 & 26.9 & 2.6 & 0.6 & & 3.9 & & \\
\hline 39 & Oosterschelde kustzone & OOSTSDKZNE & 24 / mei / 2016 & 1 & 3.4 & 26.3 & 2.5 & 0.9 & & 4.2 & & \\
\hline 40 & Oosterschelde kustzone & OOSTSDKZNE & 24 / mei / 2016 & 2 & 3.4 & 26.7 & 2.7 & 0.7 & 0.0 & & 0 & \\
\hline
\end{tabular}




\section{Bijlage 2g. Resultaten individuele Purperslakken Westerschelde kustzone}

\begin{tabular}{|c|c|c|c|c|c|c|c|c|c|c|c|c|}
\hline Nr. & Locatie & $\begin{array}{l}\text { DONAR } \\
\text { locatie }\end{array}$ & $\begin{array}{c}\text { Bemonster } \\
\text { datum }\end{array}$ & $\begin{array}{c}\text { Geslacht } \\
M=1 \\
\mathrm{~V}=2 \\
\mathrm{p}=3\end{array}$ & $\begin{array}{c}\text { Totale } \\
\text { gewicht } \\
\text { (g - } 1 \\
\text { dec) }\end{array}$ & $\begin{array}{l}\text { Lengte } \\
\text { schelp } \\
\text { (mm - } \\
1 \mathrm{dec})\end{array}$ & $\begin{array}{c}\text { Gewicht } \\
\text { schelp } \\
\text { (g - } 1 \\
\text { dec) }\end{array}$ & $\begin{array}{c}\text { Gewicht } \\
\text { vlees } \\
\text { (g-1dec) }\end{array}$ & $\begin{array}{c}\text { Penislengte } \\
\text { vrouw } \\
(\mathrm{mm}-1 \mathrm{dec})\end{array}$ & $\left(\begin{array}{c}\text { Penislengte } \\
\text { man } \\
(\mathrm{mm}-1 \mathrm{dec})\end{array}\right)$ & $\begin{array}{r}S t \\
0,1,2,3\end{array}$ & $\begin{array}{l}\mathrm{m} \\
, \mathrm{b}, \mathrm{c} \text { etc }\end{array}$ \\
\hline 1 & Westerschelde kustzone & WESTSDKZNE & 24 / mei / 2016 & 1 & 7.4 & 32.9 & 6.9 & 0.5 & & 4.4 & & \\
\hline 2 & Westerschelde kustzone & WESTSDKZNE & 24 / mei / 2016 & 2 & 6.6 & 33.0 & 5.8 & 0.8 & 0.0 & & 0 & \\
\hline 3 & Westerschelde kustzone & WESTSDKZNE & $24 / \mathrm{mei} / 2016$ & 2 & 6.2 & 32.0 & 5.3 & 0.9 & 0.0 & & 0 & \\
\hline 4 & Westerschelde kustzone & WESTSDKZNE & 24 / mei / 2016 & 1 & 6.4 & 30.2 & 5.5 & 0.9 & & 4.2 & & \\
\hline 5 & Westerschelde kustzone & WESTSDKZNE & 24 / mei / 2016 & 2 & 6.4 & 31.8 & 5.5 & 0.9 & 0.0 & & 0 & \\
\hline 6 & Westerschelde kustzone & WESTSDKZNE & 24 / mei / 2016 & 1 & 5.7 & 32.8 & 4.8 & 0.9 & & 4.2 & & \\
\hline 7 & Westerschelde kustzone & WESTSDKZNE & 24 / mei / 2016 & 2 & 7.3 & 33.2 & 6.2 & 1.1 & 0.0 & & 1 & c \\
\hline 8 & Westerschelde kustzone & WESTSDKZNE & 24 / mei / 2016 & 2 & 6.3 & 30.8 & 5.5 & 0.8 & 0.0 & & 0 & \\
\hline 9 & Westerschelde kustzone & WESTSDKZNE & $24 / \mathrm{mei} / 2016$ & 2 & 8.1 & 33.9 & 7.3 & 0.8 & 0.0 & & 0 & \\
\hline 10 & Westerschelde kustzone & WESTSDKZNE & 24 / mei / 2016 & 2 & 6.5 & 33.4 & 5.2 & 1.3 & 0.0 & & 0 & \\
\hline 11 & Westerschelde kustzone & WESTSDKZNE & 24 / $\mathrm{mei} / 2016$ & 2 & 5.5 & 30.3 & 4.8 & 0.7 & 0.7 & & 1 & a \\
\hline 12 & Westerschelde kustzone & WESTSDKZNE & 24 / mei / 2016 & 1 & 5.4 & 29.1 & 4.5 & 0.9 & & 5.2 & & \\
\hline 13 & Westerschelde kustzone & WESTSDKZNE & 24/mei / 2016 & 2 & 6.1 & 32.8 & 5.0 & 1.1 & 0.0 & & 0 & \\
\hline 14 & Westerschelde kustzone & WESTSDKZNE & $24 /$ mei / 2016 & 2 & 5.8 & 30.3 & 4.8 & 1.0 & 0.0 & & 0 & \\
\hline 15 & Westerschelde kustzone & WESTSDKZNE & 24 / mei / 2016 & 1 & 6.2 & 31.4 & 5.2 & 1.0 & & 4.5 & & \\
\hline 16 & Westerschelde kustzone & WESTSDKZNE & 24 / mei / 2016 & 2 & 6.6 & 32.3 & 5.4 & 1.2 & 0.0 & & 0 & \\
\hline 17 & Westerschelde kustzone & WESTSDKZNE & 24 / mei / 2016 & 2 & 6.1 & 30.8 & 4.7 & 1.4 & 0.0 & & 0 & \\
\hline 18 & Westerschelde kustzone & WESTSDKZNE & 24 / mei / 2016 & 2 & 6.1 & 31.7 & 4.9 & 1.2 & 0.0 & & 0 & \\
\hline 19 & Westerschelde kustzone & WESTSDKZNE & 24 / mei / 2016 & 1 & 6.3 & 32.6 & 5.1 & 1.2 & & 4.8 & & \\
\hline 20 & Westerschelde kustzone & WESTSDKZNE & 24 / mei / 2016 & 1 & 4.8 & 29.0 & 3.9 & 0.9 & & 5.0 & & \\
\hline 21 & Westerschelde kustzone & WESTSDKZNE & 24 / mei / 2016 & 2 & 5.3 & 29.6 & 4.6 & 0.7 & 0.0 & & 0 & \\
\hline 22 & Westerschelde kustzone & WESTSDKZNE & 24 / mei / 2016 & 2 & 4.2 & 29.3 & 3.7 & 0.5 & 0.5 & & 1 & a \\
\hline 23 & Westerschelde kustzone & WESTSDKZNE & 24 / mei / 2016 & 1 & 5.4 & 30.4 & 4.5 & 0.9 & & 4.5 & & \\
\hline 24 & Westerschelde kustzone & WESTSDKZNE & $24 / \mathrm{mei} / 2016$ & 1 & 4.3 & 29.4 & 3.4 & 0.9 & & 1.0 & & \\
\hline 25 & Westerschelde kustzone & WESTSDKZNE & 24 / mei / 2016 & 2 & 7.2 & 34.1 & 6.1 & 1.1 & 0.0 & & 0 & \\
\hline 26 & Westerschelde kustzone & WESTSDKZNE & 24 / mei / 2016 & 1 & 4.7 & 30.6 & 4.0 & 0.7 & & 4.2 & & \\
\hline 27 & Westerschelde kustzone & WESTSDKZNE & $24 / \mathrm{mei} / 2016$ & 1 & 3.9 & 27.9 & 3.2 & 0.7 & & 4.5 & & \\
\hline 28 & Westerschelde kustzone & WESTSDKZNE & 24 / mei / 2016 & 1 & 4.3 & 28.6 & 3.6 & 0.7 & & 4.7 & & \\
\hline 29 & Westerschelde kustzone & WESTSDKZNE & $24 / \mathrm{mei} / 2016$ & 1 & 7.1 & 32.5 & 6.0 & 1.1 & & 4.2 & & \\
\hline 30 & Westerschelde kustzone & WESTSDKZNE & $24 / \mathrm{mei} / 2016$ & 1 & 5.2 & 28.1 & 4.5 & 0.7 & & 4.8 & & \\
\hline 31 & Westerschelde kustzone & WESTSDKZNE & 24 / mei / 2016 & 2 & 6.5 & 31.1 & 5.3 & 1.2 & 0.0 & & 0 & \\
\hline 32 & Westerschelde kustzone & WESTSDKZNE & $24 / \mathrm{mei} / 2016$ & 1 & 6.0 & 31.1 & 4.7 & 1.3 & & 4.9 & & \\
\hline 33 & Westerschelde kustzone & WESTSDKZNE & $24 / \mathrm{mei} / 2016$ & 2 & 6.1 & 30.1 & 5.6 & 0.5 & 0.0 & & 0 & \\
\hline 34 & Westerschelde kustzone & WESTSDKZNE & $24 / \mathrm{mei} / 2016$ & 1 & 6.1 & 30.1 & 5.4 & 0.7 & & 4.3 & & \\
\hline 35 & Westerschelde kustzone & WESTSDKZNE & $24 / \mathrm{mei} / 2016$ & 1 & 3.0 & 23.7 & 2.5 & 0.5 & & 3.2 & & \\
\hline 36 & Westerschelde kustzone & WESTSDKZNE & 24 / mei / 2016 & 1 & 4.6 & 28.1 & 3.8 & 0.8 & & 5.2 & & \\
\hline 37 & Westerschelde kustzone & WESTSDKZNE & $24 / \mathrm{mei} / 2016$ & 2 & 3.5 & 25.3 & 3.1 & 0.4 & 0.0 & & 0 & \\
\hline 38 & Westerschelde kustzone & WESTSDKZNE & $24 / \mathrm{mei} / 2016$ & 2 & 4.1 & 29.1 & 3.2 & 0.9 & 0.0 & & 0 & \\
\hline 39 & Westerschelde kustzone & WESTSDKZNE & $24 / \mathrm{mei} / 2016$ & 2 & 4.6 & 29.2 & 3.9 & 0.7 & 0.0 & & 0 & \\
\hline 40 & Westerschelde kustzone & WESTSDKZNE & 24 / mei / 2016 & 1 & 4.6 & 30.0 & 3.8 & 0.8 & & 4.3 & & \\
\hline
\end{tabular}


Bijlage 3. Gehalten aan organotinverbindingen in 2016

\begin{tabular}{|c|c|c|c|c|c|c|c|c|c|c|}
\hline Requestnummer & Monsternummer & Monstersoort & Monsterdatum & Vangstgebied & $\begin{array}{c}\text { Dibutyltin } \\
\mu \mathrm{g} / \mathrm{kg} \\
\mathrm{Q}\end{array}$ & $\begin{array}{c}\text { Dibutyltin } \\
\text { kation } \\
\mu \mathrm{g} / \mathrm{kg} \\
\mathrm{Q} \\
\end{array}$ & $\begin{array}{c}\text { Diphenyltin } \\
\mu \mathrm{g} / \mathrm{kg}\end{array}$ & $\begin{array}{c}\text { Diphenyltin } \\
\text { kation } \\
\mu \mathrm{g} / \mathrm{kg}\end{array}$ & $\begin{array}{c}\text { Monobutyltin } \\
\mu \mathrm{g} / \mathrm{kg}\end{array}$ & $\begin{array}{l}\text { Monobutyltin } \\
\text { kation } \\
\mu g / k g\end{array}$ \\
\hline RQ20160203/012 & $2016 / 0625$ & Alikruik & $22 / 06 / 2016$ & Waddenzee kustzone oost & 0.5 & 0.9 & $<0.2$ & $<0.4$ & 0.3 & 0.4 \\
\hline RQ20160203/013 & $2016 / 0666$ & Alikruik & $22 / 06 / 2016$ & Waddenzee kustzone west & 0.2 & 0.4 & $<0.1$ & $<0.2$ & 0.1 & 0.2 \\
\hline RQ20160203/014 & $2016 / 0707$ & Gevlochten fuikhoorn & $05 / 04 / 2016$ & Hollandse kustzone noord & 0.3 & 0.6 & $<0.2$ & $<0.4$ & $<0.2$ & $<0.3$ \\
\hline RQ20160204/015 & $2016 / 0748$ & Gevlochten fuikhoorn & $05 / 04 / 2016$ & Hollandse kustzone midden & 0.1 & 0.3 & $<0.1$ & $<0.3$ & $<0.1$ & $<0.2$ \\
\hline RQ20160204/016 & $2016 / 0789$ & Gevlochten fuikhoorn & $04 / 04 / 2016$ & Hollandse kustzone zuid & 0.2 & 0.5 & $<0.1$ & $<0.3$ & $<0.1$ & $<0.2$ \\
\hline RQ20160204/017 & $2016 / 0830$ & Gevlochten fuikhoorn & 09/05/2016 & Haringvliet kustzone & $<0.1$ & $<0.3$ & $<0.1$ & $<0.3$ & $<0.2$ & $<0.2$ \\
\hline RQ20160204/018 & $2016 / 0871$ & Purperslak & $24 / 05 / 2016$ & Grevelingen kustzone & $<0.2$ & $<0.3$ & $<0.2$ & $<0.4$ & $<0.2$ & $<0.3$ \\
\hline RQ20160204/019 & $2016 / 0912$ & Purperslak & $24 / 05 / 2016$ & Oosterschelde kustzone & $<0.1$ & $<0.3$ & $<0.1$ & $<0.3$ & $<0.1$ & $<0.2$ \\
\hline RQ20160204/020 & $2016 / 0953$ & Purperslak & $24 / 05 / 2016$ & Westerschelde kustzone & 0.5 & 1.0 & $<0.1$ & $<0.3$ & $<0.2$ & $<0.2$ \\
\hline
\end{tabular}

\begin{tabular}{|c|c|c|c|c|c|c|c|c|c|c|c|}
\hline Requestnummer & Monsternummer & Monstersoort & Monsterdatum & Vangstgeb. Mariene slak & $\begin{array}{c}\text { Monophenyltin } \\
\mu \mathrm{g} / \mathrm{kg}\end{array}$ & \begin{tabular}{|c|} 
Monophenyltin \\
kation \\
$\mu \mathrm{g} / \mathrm{kg}$
\end{tabular} & $\begin{array}{c}\text { Tributyltin } \\
\mu \mathrm{g} / \mathrm{kg} \\
\mathrm{Q}\end{array}$ & $\begin{array}{c}\text { Tributyltin } \\
\text { kation } \\
\mu g / k g \\
Q\end{array}$ & $\begin{array}{l}\text { Triphenyltin } \\
\mu \mathrm{g} / \mathrm{kg}\end{array}$ & $\begin{array}{c}\text { Triphenyltin } \\
\text { kation } \\
\mu \mathrm{g} / \mathrm{kg}\end{array}$ & $\begin{array}{c}\text { Droge stof } \\
\quad \% \\
Q\end{array}$ \\
\hline RQ20160203/012 & $2016 / 0625$ & Alikruik & $22 / 06 / 2016$ & Waddenzee kustzone oost & $<0.2$ & $<0.3$ & 1.2 & 3.0 & $<0.1$ & $<0.5$ & 20.8 \\
\hline RQ20160203/013 & $2016 / 0666$ & Alikruik & $22 / 06 / 2016$ & Waddenzee kustzone west & $<0.1$ & $<0.2$ & 0.9 & 2.1 & $<0.08$ & $<0.3$ & 18.2 \\
\hline RQ20160203/014 & 2016/0707 & Gevlochten fuikhoorn & $05 / 04 / 2016$ & Hollandse kustzone noord & $<0.2$ & $<0.3$ & 1.1 & 2.6 & $<0.1$ & $<0.4$ & 30.5 \\
\hline RQ20160204/015 & $2016 / 0748$ & Gevlochten fuikhoorn & $05 / 04 / 2016$ & Hollandse kustzone midden & $<0.1$ & $<0.2$ & 0.6 & 1.4 & $<0.1$ & $<0.3$ & 28.8 \\
\hline RQ20160204/016 & $2016 / 0789$ & Gevlochten fuikhoorn & $04 / 04 / 2016$ & Hollandse kustzone zuid & $<0.1$ & $<0.2$ & 0.9 & 2.1 & $<0.09$ & $<0.3$ & 31.2 \\
\hline RQ20160204/017 & $2016 / 0830$ & Gevlochten fuikhoorn & $09 / 05 / 2016$ & Haringvliet kustzone & $<0.1$ & $<0.2$ & 1.0 & 2.5 & $<0.1$ & $<0.3$ & 28.1 \\
\hline RQ20160204/018 & $2016 / 0871$ & Purperslak & $24 / 05 / 2016$ & Grevelingen kustzone & $<0.2$ & $<0.3$ & 1.2 & 2.8 & $<0.1$ & $<0.4$ & 25.7 \\
\hline RQ20160204/019 & $2016 / 0912$ & Purperslak & $24 / 05 / 2016$ & Oosterschelde kustzone & $<0.1$ & $<0.2$ & 1.1 & 2.6 & $<0.1$ & $<0.3$ & 26.4 \\
\hline RQ20160204/020 & $2016 / 0953$ & Purperslak & $24 / 05 / 2016$ & Westerschelde kustzone & $<0.1$ & $<0.2$ & 3.1 & 7.6 & $<0.1$ & $<0.3$ & 29.7 \\
\hline
\end{tabular}

$\mathrm{Q}=1 \mathrm{SO} 17025$

Gehalten in $\mu g / k g$ nat gew icht

Alle gehalten zijn met kw aitteitsw aardecode 0 (normale w aarde) gerapporteerd in DONAR. 


\section{Bijlage 4.1 Resultaten referentiematerialen}

\begin{tabular}{|c|c|c|c|c|c|c|c|c|c|}
\hline Component & Referentiemateriaal & IMARES-waarde & $\mathrm{n}$ & IMARES-waarde & $n$ & $\mathrm{ng} / \mathrm{dg}$ & gecertificeerde waarde & eenheid & kwalificatie \\
\hline & & in 2016 & in 2016 & QC-kaart & totaal & & & & \\
\hline TBT als kation & CRM CE477 (mossel) & 2193.8 & 1 & $2179.6 \pm 393.6$ & 34 & $\mathrm{dg}$ & $2200 \pm 190$ & $\mu \mathrm{g} / \mathrm{kg}$ & goed \\
\hline DBT als kation & CRM CE477 (mossel) & 1428.5 & 1 & $1403.8 \pm 315.5$ & 34 & $\mathrm{dg}$ & $1540 \pm 120$ & $\mu \mathrm{g} / \mathrm{kg}$ & goed \\
\hline MBT als kation & CRM CE477 (mossel) & 1653 & 1 & $1536.6 \pm 389.0$ & 34 & $\mathrm{dg}$ & $1500 \pm 280$ & $\mu \mathrm{g} / \mathrm{kg}$ & goed \\
\hline Vocht & haring/makreel IRM 2005/0775 & $70.10 \pm 0.35$ & 8 & $70.00 \pm 0.50$ & 238 & $\mathrm{ng}$ & n.v.t. & $\%$ & goed \\
\hline
\end{tabular}




\section{Bijlage 4.2 Resultaten ringonderzoek Quasimeme in biota (labcode: Q127}

\section{MARES)}

\begin{tabular}{|c|c|c|c|c|c|c|c|c|c|}
\hline Group & Round & Period & Matrix & Determinand & Unit & Z-score & Qualification & Comment & accreditatie \\
\hline BT8 & 2015,1 & apr 2015-aug 2015 & QSP052BT & TBT & $\mu \mathrm{g} / \mathrm{kg}$ & -1.73 & Satisfactory & & ja \\
\hline BT8 & 2015,1 & apr 2015-aug 2015 & QSP053BT & TBT & $\mu \mathrm{g} / \mathrm{kg}$ & 1.87 & Satisfactory & niet ingediend & ja \\
\hline BT8 & 2015,1 & apr 2015-aug 2015 & QSP052BT & DBT & $\mu \mathrm{g} / \mathrm{kg}$ & -0.46 & Satisfactory & & ja \\
\hline BT8 & 2015,1 & apr 2015-aug 2015 & QSP053BT & DBT & $\mu \mathrm{g} / \mathrm{kg}$ & 0.60 & Satisfactory & niet ingediend & ja \\
\hline BT8 & 2015,1 & apr 2015-aug 2015 & QSP052BT & MBT & $\mu \mathrm{g} / \mathrm{kg}$ & 0.42 & Satisfactory & & nee \\
\hline BT1 & 2015,1 & apr 2015-aug 2015 & QTM105BT & droge stof & $\%$ & -0.13 & Satisfactory & & ja \\
\hline BT1 & 2015,1 & apr 2015-aug 2015 & QTM106BT & droge stof & $\%$ & -0.06 & Satisfactory & & ja \\
\hline BT8 & 2015,2 & okt 2015-jan 2016 & QSP054BT & TBT & $\mu \mathrm{g} / \mathrm{kg}$ & 6.12 & Unsatisfactory & Storende piek & ja \\
\hline BT8 & 2015,2 & okt 2015-jan 2016 & QSP055BT & TBT & $\mu \mathrm{g} / \mathrm{kg}$ & 2.53 & Questionable & Storende piek & ja \\
\hline BT8 & 2015,2 & okt 2015-jan 2016 & QSP055BT & DBT & $\mu \mathrm{g} / \mathrm{kg}$ & -0.27 & Satisfactory & & ja \\
\hline BT8 & 2015,2 & okt 2015-jan 2016 & QSP055BT & MBT & $\mu \mathrm{g} / \mathrm{kg}$ & -2.35 & Questionable & & nee \\
\hline BT1 & 2015,2 & okt 2015-jan 2016 & QTM107BT & droge stof & $\%$ & 0.20 & Satisfactory & & ja \\
\hline BT1 & 2015,2 & okt 2015-jan 2016 & QTM108BT & droge stof & $\%$ & 0.10 & Satisfactory & & ja \\
\hline BT8 & 2016,1 & apr 2016-jul 2016 & QSP056BT & TBT & $\mu \mathrm{g} / \mathrm{kg}$ & 2.60 & Questionable & Storende piek & ja \\
\hline BT8 & 2016,1 & apr 2016-jul 2016 & QSP057BT & TBT & $\mu \mathrm{g} / \mathrm{kg}$ & 0.99 & Satisfactory & Storende piek & ja \\
\hline BT8 & 2016,1 & apr 2016-jul 2016 & QSP056BT & DBT & $\mu \mathrm{g} / \mathrm{kg}$ & 0.14 & Satisfactory & niet ingediend & ja \\
\hline BT8 & 2016,1 & apr 2016-jul 2016 & QSP057BT & DBT & $\mu \mathrm{g} / \mathrm{kg}$ & -0.64 & Satisfactory & niet ingediend & ja \\
\hline BT8 & 2016,1 & apr 2016-jul 2016 & QSP056BT & MBT & $\mu \mathrm{g} / \mathrm{kg}$ & -1.28 & Satisfactory & niet ingediend & nee \\
\hline BT8 & 2016,1 & apr 2016-jul 2016 & QSP057BT & MBT & $\mu \mathrm{g} / \mathrm{kg}$ & -2.04 & Questionable & niet ingediend & nee \\
\hline BT1 & 2016,1 & apr 2016-jul 2016 & QTM109BT & droge stof & $\%$ & -0.32 & Satisfactory & & ja \\
\hline BT1 & 2016,1 & apr 2016-jul 2016 & QTM110BT & droge stof & $\%$ & -0.03 & Satisfactory & & ja \\
\hline
\end{tabular}

De resultaten in bovenstaande tabel waarbij "niet ingediend" staat aangegeven, hebben wij vanwege logistieke redenen op een later tijdstip bepaald en zelf de Z-scores berekend (zie ook paragraaf 3.3). Deze resultaten zijn dus niet gerapporteerd aan Quasimeme.

Indien een z-score de kwalificatie 'unsatisfactory' heeft gekregen wordt daarop, vastgelegd in ons kwaliteitssysteem, adequaat actie ondernomen. De betekenissen van de kwalificaties, zoals door Quasimeme toegekend, zijn als volgt:
Satisfactory:
$|Z|<2$, resultaat voldoet
Unsatisfactory:
$|Z|>3$, resultaat voldoet niet (adequate actie vereist)
Questionable:
$|Z|<3$, resultaat is twijfelachtig (geen actie vereist)

Consistent:

er is een waarde $(x)<$ rapportagegrens door het deelnemend lab

gerapporteerd, deze waarde was in overeenstemming met de assigned value (consensus waarde), bv. $<0.03$ gerapporteerd, terwijl assigned value 0.02 is

Inconsistent: er is een waarde $(x)<$ rapportagegrens door het deelnemend lab gerapporteerd, deze waarde was niet in overeenstemming met de assigned value (consensus waarde), bv. $<0.03$ gerapporteerd, terwijl assigned value 0.06 is

Blanc: geen z-score bepaald door Quasimeme (mogelijke oorzaken: te weinig laboratoria hebben resultaten gerapporteerd of de spreiding van de resultaten tussen de laboratoria onderling was te groot) 


\section{Bijlage 4.3 Rapportagegrenzen en meetonzekerheid}

\begin{tabular}{|c|c|c|c|c|c|c|c|}
\hline Component & rapportage- & detectie- & unit & $\mathrm{ng} / \mathrm{dg}$ & $\mathrm{v}_{\mathrm{c}}$ & $\mathrm{n}$ & $\mathrm{d}_{\mathrm{c}}$ \\
\hline & grens & limiet & & & rel. standard uncertainty (\%) & & $(\mu \mathrm{g} / \mathrm{kg})$ \\
\hline TBT als Sn & 0.1 & & $\mu \mathrm{g} / \mathrm{kg}$ & $\mathrm{ng}$ & 24.5 & 9 & 0 \\
\hline DBT als Sn & 0.1 & & $\mu \mathrm{g} / \mathrm{kg}$ & $\mathrm{ng}$ & 14.7 & 19 & 0 \\
\hline MBT als Sn & 0.2 & & $\mu \mathrm{g} / \mathrm{kg}$ & ng & 25.3 & 9 & 0 \\
\hline TPhT als Sn & 0.1 & & $\mu \mathrm{g} / \mathrm{kg}$ & $\mathrm{ng}$ & niet vastgesteld & & \\
\hline DPhT als Sn & 0.1 & & $\mu \mathrm{g} / \mathrm{kg}$ & $\mathrm{ng}$ & niet vastgesteld & & \\
\hline MPhT als Sn & 0.1 & & $\mu \mathrm{g} / \mathrm{kg}$ & $\mathrm{ng}$ & niet vastgesteld & & \\
\hline TBT als kation & 0.3 & & $\mu \mathrm{g} / \mathrm{kg}$ & $\mathrm{ng}$ & 24.5 & 9 & 0 \\
\hline DBT als kation & 0.3 & & $\mu \mathrm{g} / \mathrm{kg}$ & $\mathrm{ng}$ & 14.7 & 19 & 0 \\
\hline MBT als kation & 0.2 & & $\mu \mathrm{g} / \mathrm{kg}$ & $\mathrm{ng}$ & 25.3 & 9 & 0 \\
\hline TPhT als kation & 0.3 & & $\mu \mathrm{g} / \mathrm{kg}$ & $\mathrm{ng}$ & niet vastgesteld & & \\
\hline DPhT als kation & 0.3 & & $\mu \mathrm{g} / \mathrm{kg}$ & $\mathrm{ng}$ & niet vastgesteld & & \\
\hline MPhT als kation & 0.2 & & $\mu \mathrm{g} / \mathrm{kg}$ & $\mathrm{ng}$ & niet vastgesteld & & \\
\hline droge stof & 1 & 0.5 & $\%$ & $\mathrm{ng}$ & 3.7 & 48 & 0 \\
\hline \multicolumn{8}{|c|}{ op basis van juistheidsbepaling en monsterinhomogeniteit } \\
\hline \multicolumn{8}{|c|}{ verwaarloosbaar klein } \\
\hline \multicolumn{8}{|c|}{$\mathrm{n}=$ aantal ringonderzoeken aan de hand waarvan een Z-score bepaald kon worden } \\
\hline \multicolumn{8}{|c|}{$d_{c}$ is de combined constant error in de eenheid van de concentratie van de component } \\
\hline
\end{tabular}

De RMS (root mean square) wordt berekend volgens NEN 7779 als basis voor de gecombineerde meetonzekerheid (standard uncertainty) uit de resultaten van verschillende ringonderzoeken (verschillende matrices) van meerdere rondes $(n>8)$. De relatieve uitgebreide meetonzekerheid (expanded uncertainty) is gedefinieerd als twee maal de relatieve standard uncertainty. De relatieve standard uncertainty is weergegeven in bijlage 4.3. Hierin zijn de reproduceerbaarheid, de tussenmonster-spreiding en de methode juistheid verwerkt. Eventuele inhomogeniteit van het monster is hier niet in verwerkt, maar is bij ringonderzoekmonsters niet van toepassing.

Voor de rapportage aan OSPAR dient bij iedere meetwaarde de expanded uncertainty (95\% betrouwbaarheidsinterval) berekend te worden. De expanded uncertainty is gedefinieerd als tweemaal de standaard deviatie. Voor OSPAR dient dus een absolute meetonzekerheid gerapporteerd te worden. De berekening van de absolute expanded uncertainty is gebaseerd op onderstaande formules uit de OSPAR guideline voor de bepaling van de meetonzekerheid. De relative standard uncertainty (uitgedrukt in \%) wordt door IMARES als maat voor de $v_{c}$ gehanteerd. In bijlage 4.3 zijn zowel de relative standard uncertainty $\left(=v_{c}\right)$ als de constant error $\left(=d_{c}\right)$ opgenomen. Beide dienen als input in de formules voor de berekening van de absolute expanded uncertainty.

Formules uit de OSPAR quideline:

$s_{C}=\sqrt{d_{C}^{2}+\left(\frac{v_{c}}{100}\right)^{2} C^{2}}$

waarin:

$\mathrm{S}_{\mathrm{c}}=$ standard deviation (eenheid = eenheid van concentratie component)

$\mathrm{d}_{\mathrm{c}}=$ "combined constant error" (eenheid = eenheid van concentratie component) 
$\mathrm{v}_{\mathrm{c}}=$ variatie coëfficiënt (eenheid= percentage)

$\mathrm{C}=$ concentratie van de component in het monster (meetwaarde)

$U_{C}=2 s_{C}$

waarin:

$\mathrm{U}_{\mathrm{c}}=$ (absolute) expanded uncertainty (eenheid = eenheid van concentratie component)

Voor componenten waarvoor geen deelname plaatsvindt aan ringonderzoeken is, indien mogelijk, de meetonzekerheid vastgesteld op basis van juistheidsbepaling en monsterinhomogeniteit. Voor

componenten waarvoor zowel geen ringonderzoeken als geen referentiematerialen voorhanden zijn, kan de meetonzekerheid niet worden vastgesteld. Voor componenten waarvoor het aantal deelgenomen rondes aan ringonderzoeken minder bedraagt dan 8, kan nog geen meetonzekerheid worden vastgesteld volgens NEN 7779. 